\title{
Transformação forma urbana e localização de renda: identificação de padrões nas cidades brasileiras ${ }^{1}$
}

\author{
Jonathas Magalhães Pereira da Silva, \\ Camila Galli Romera, Ana Carolina Vieira Gonçalves*
}

\begin{abstract}
Resumo O presente texto investiga a relação espacial existente entre a renda da população e a forma urbana. Considerando que a sociedade brasileira é caracterizada pela concentração de renda, torna-se pertinente verificar a influência dos padrões de renda na constituição das cidades. A pesquisa produziu 166 mapas de renda de cidades brasileiras. O método de espacializar a renda permite aferir a composição das rendas de cada setor censitário. Na analise comparativa entre municípios pode-se identificar sete grupos que possuem características similares na distribuição espacial dos padrões de renda. Estes grupos demonstram ter distintas formas de influência sobre a constituição da forma urbana e do sistema de espaços livres. Os resultados apontam padrões que passam a ser considerados na discussão da Forma Urbana.
\end{abstract}

Palavras-chave: forma urbana, renda, morfologia.

\section{Transformation of the urban form and lo- cation of income: identification of patterns in brazilian cities}

\begin{abstract}
The present work aims to understand if there is a relationship between the incomes of the population and the urban form. Considering that Brazilian society is characterized by income concentration, it is pertinent to verify the influence of income patterns in the constitution of the urban form. This article analyzes the 166 income maps of Brazilian cities produced by the research. The method of spatializing income allows one to consider the composition of rents for each census sector. In the comparative analysis between municipalities we could identify seven city patterns. These groups seem to have different forms of influence on the creation of open spaces system. The result indicates patterns that could assist in the discussion of the Urban Form.
\end{abstract}

Keywords: urban form, income, morphology.

\section{Transformación forma urbana y ubicación de ingresos: identificación de estándares en las ciudades brasileñas}

Resumen El presente texto investiga la relación entre los ingresos de la población y la forma urbana. Considerando que la sociedad brasileña es caracterizada por la concentración de renta, resulta pertinente verificar la influencia de los patrones de renta en la constitución de la forma urbana. La investigación produjo 166 mapas de renta de ciudades brasileñas producidos por la investigación. El método de espacializar la renta permite medir la composición de los ingresos de cada sector censitario. En el análisis comparativo entre municipios se pueden identificar siete patrones distintos de distribución de renta en las ciudades estudiadas. Estos grupos parecen tener distintas formas de influencia sobre la constitución de la forma urbana y del sistema de espacios libres. Los resultados apuntan patrones que pasan a ser considerados en la discusión de la Forma Urbana.

Palabras clave: forma urbana, ingresos, morfología. 
* Jonathas Magalhães Pereira da Silva é Arquiteto e Urbanista, professor da Pontifícia Universidade Católica de Campinas, ORCID <https://orcid.org/00000002-8186-9626>. Camila Galli Romera é Graduanda em Arquitetura e Urbanismo, Faculdade de Arquitetura e Urbanismo da Pontifícia Universidade Católica de Campinas; Ana Carolina Vieira Gonçalves é Graduanda em Arquitetura e Urbanismo, Faculdade de Arquitetura e Urbanismo da Pontifícia Universidade Católica de Campinas. presente texto é fruto do esforço de incorporar os dados de renda na análise de pesquisas que tem como objeto o estudo da forma urbana. Analisa os dados referentes às rendas do representante do domicílio coletadas pelo IBGE no censo de 2010 e relaciona com os padrões morfológicos existentes. Tem por objetivo identificar possíveis relações existentes entre as localizações das rendas e a forma urbana. Os resultados encontrados abrem para uma série de questões que passamos a compartilhar. A percepção da importância de incorporar dados de renda para discutir a forma urbana da cidade se baseia em diferentes autores (MALDONADO, 2007; SINGER, 1979; VILAÇA, 2001) que não tratam do assunto diretamente mas ajudam a revelar uma organização das cidades em função do valor do solo, da mobilidade e da renda.

Ao tomar os dados do IBGE de 2010 deve-se considerar que o período analisado é de forte expansão do assalariamento formal e queda do desemprego fruto da implementação de políticas sociais de distribuição de renda, assim como, a retomada do crescimento econômico (GUIMARÃES, 2012).

o padrão de expansão do emprego na última década implicou, de modo geral, uma melhoria relativa dos postos de trabalho: as ocupações criadas se concentram nos quintos mais altos de renda (melhoria de emprego). A literatura econômica - principalmente por meio da hipótese de skill biased technological change, tanto em sua versão original quanto na de Autor, Levy e Murnane (2003) - indica que esse quadro pode estar ligado ao aumento da desigualdade observado em uma séria de países desenvolvidos, uma vez que reflete o aquecimento da demanda por mais altas qualificações (e, por conseguinte, a elevação dos prêmios salariais). Nossos resultados mostram que, no Brasil, esse tipo de tendência não se aplica: experimentamos queda em todos os índices que mensuram a desigualdade de rendimentos ao mesmo tempo que vivenciávamos significativas mudanças no mercado de trabalho, um job upgrading. CARVALHAES, 2014; pg. 94

A organização dos dados possibilitará o cotejamento com os dados que serão recolhidos pelo censo de 2020 com contexto econômico diverso. Cabe alertar que existem diferentes caminhos para se estudar a questão de renda. É comum buscar entender os aspectos que estruturam o nível de renda dos indivíduos por meio da associação de multivariaveis. (SANTOS, 2002); ou de estabelecer métodos para decompor indicadores sintéticos de desigualdade de renda (LEMIEUX, 2006); ou ainda buscar entender quais são os fatores mais importantes na estruturação da renda (CARVALHAES, 2000). Entretanto poucos trabalhos estudam os padrões de distribuição espacial dos diferentes padrões de renda nas cidades brasileiras. A presente análise identifica, entre os 166 municípios mapeados, sete grupos de cidades com distintas características de distribuição espacial. A pesquisa se ocupa de compreender a distribuição espacial da renda na cidade. O método proposto trabalha com a identificação dos padrões e sua relação com a forma urbana. 
1 As questões aqui apresentadas são fruto de pesquisa apoiada pelo CNPq por meio do edital universal intitulada "Os papéis dos investimentos públicos: uma análise do sistema de Espaços Livres e da Habitação de Interesse Social na constituição da forma urbana".

2 A Região Metropolitana de Campinas foi o recorte territorial estabelecido pela pesquisa apoiada pelo CNPq por meio do edital universal intitulada "Os Papeis Dos Investimentos Públicos: Uma Analise Do Sistema De Espaços Livres e da Habitação de Interesse Social na Constituição da Forma Urbana".

O objetivo foi analisar as coexistências de diferentes faixas de renda em um mesmo setor censitário e relacionar com as características da forma urbana do setor. O método de mapeamento trabalha com a composição das rendas existentes nos setores censitários ao invés de trabalhar com a média de renda de cada setor. Desta forma possibilita caracterizar a composição das faixas de renda dentro dos setores censitários, o que possibilita por sua vez analisar com razoável precisão a distribuição espacial das faixas de renda sobre o território municipal e metropolitano.

O grupo de pesquisa Quadro do Paisagismo (QUAPA-SEL) junto ao grupo Políticas Territoriais e a Água no meio Urbano (PosUrb-Arq - PUC-Campinas) ${ }^{2}$ vem desenvolvendo diferentes cartografias que têm por objetivo analisar a transformação da forma urbana. Toma-se o conceito de morfologia onde a investigação da forma decorre do entendimento dos fenômenos que lhe deram origem (LAMAS, 1992). Portanto para o entendimento da forma urbana faz-se necessário levar em conta como ocorrem os processos socioeconômicos. Não basta entender seus aspectos físicos, mas sim, compreender como "processo e produto" constituem a paisagem contemporânea das cidades brasileiras (MACEDO, 2008). A contribuição da presente investigação foi produzir mapas de renda para os 166 municípios distribuídos por 23 estados brasileiros. Neste percurso uma serie de indagações ajudaram a avançar nos procedimentos metodológicos e na analise.

Trabalha-se com diferentes municípios brasileiros na busca de abarcar suas diferenças regionais. Foram desenvolvidos mapas de renda de municípios de 23 estados da federação, sendo um total de 166 mapas: 28 municípios estudados isoladamente, 5 regiões metropolitanas totalizando 131 municípios e a Aglomeração Urbana de Jundiaí, localizada entre as regiões metropolitanas de São Paulo e Campinas composta por 7 municípios que objetiva fomentar a discussão a respeito da chamada megametrópole paulista estudada (BENFATTI, QUEIROGA E SILVA, 2010).

Municípios estudados isoladamente:

1. Belém - Pará

3. Campina Grande - Paraíba

5. Campo Grande - Mato Grosso do Sul

7. Curitiba - Paraná

9. Fortaleza - Ceará

11. João Pessoa - Paraíba

13. Maceió - Alagoas

15. Maringá - Paraná

17. Palmas - Tocantins

19. Rio Branco - Acre

21. Salvador - Baia

23. São Carlos - São Paulo

25. Sorocaba - São Paulo

27. Uberlândia - Minas Gerais
2. Brasília - Distrito Federal

4. Campo dos Goytacazes - Rio de Janeiro

6. Criciúma - Santa Catarina

8. Florianópolis - Santa Catarina

10. Goiânia - Goiás

12. Macapá - Amapá

14. Manaus - Amazonas

16. Natal - Rio Grande do Norte

18. Recife - Pernanbuco

20. Rio de Janeiro - Rio de Janeiro

22. Santa Maria - Rio Grande do Sul

24. São Luís - Maranhão

26. Uberaba - Minas Gerais

28. Vitória - Espírito Santos 
Regiões metropolitanas:

1. Região Metropolitana de Curitiba - Paraná: 29 municípios

2. Região Metropolitana de Belo Horizonte - Minas Gerais: 34 municípios

3. Região Metropolitana de Campinas: 20 municípios

4. Região Metropolitana da Baixada Santista: 9 municípios

5. Região Metropolitana de São Paulo: 39 municípios

Regiões de interesse:

1. Região localizada entre as regiões metropolitanas de Campinas e São Paulo.

Apresentamos a seguir os resultados analíticos dos mapas gerados a partir da tabela disponibilizada pelo IBGE do censo de 2010 intitulada: "Renda da Pessoa Responsável pelo domicílio". Identificamos sete padrões distintos de distribuição espacial de rendas sendo que alguns destes padrões causam uma estranheza por não caracterizarem claramente o processo de segregação espacial existente, conforme veremos ao analisarmos a Região Metropolitana de Curitiba. Em outros casos estranha-se por constatar a presença de rendas (altas ou baixas) em localizações não esperadas. Finalmente, por meio dos estudos de caso, faz-se uma análise preliminar das relações percebidas entre o mapa de distribuição das rendas sobre o território e o mapa que caracteriza a forma urbana do município.

\section{Analise dos mapas de "Renda da Pessoa Responsável" do domicílio}

A intenção inicial de desenvolver mapas de renda era identificar as localizações das diferentes rendas monetárias sobre o território urbano de forma a reforçar a tese da existência da segregação espacial urbana. As combinações de precariedades causadas pelo processo de segregação urbana se refletem nas áreas periféricas na demanda habitacional latente, na dificuldade de acesso ao emprego, assim como, pela precariedade da infraestrutura, da mobilidade urbana e da dificuldade de acessos à equipamentos e serviços públicos.

Frente ao objetivo exposto optou-se por trabalhar com os dados de "renda da pessoa responsável" do domicílio. Inferiu-se que por meio deste dado fosse possível identificar as diferenças de renda dos responsáveis de forma que a renda não fosse mascarada pela média domiciliar, isto é, pela renda per capta domiciliar. Possibilitaria, segundo este raciocínio, identificar as diferentes oportunidades de renda monetária distribuídas pelo território. A questão colocada é qualificar espacialmente a incidência de acesso a um determinado padrão de renda, em uma determinada área urbana. $O$ resultado apontaria como varia as oportunidades de acesso às baixas, médias e altas rendas em função da localização do morador no território urbano.

Tomou-se como hipótese que por meio da renda do "responsável pelo domicílio" as altas, médias e baixas rendas mostrariam com mais eficiência o processo de segregação urbana relacionando a renda do responsável diretamente com as localizações de melhor mobilidade e acesso a oferta de emprego e aos serviços 
Figura 1: Porcentagens da população ativa relacionada à renda (unidade: salário mínimo). Fonte: Desenvolvida por Jonathas MagaIhães Pereira da Silva com base em dados do IBGE 2010.

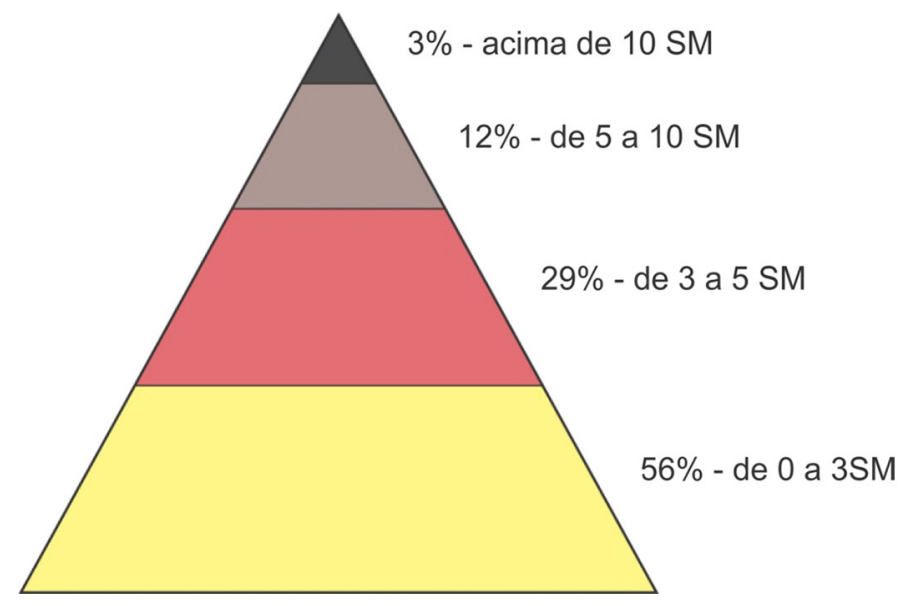

públicos urbanos. Esta seria a razão do interesse em trabalhar com a renda monetária que teoricamente acompanha as oportunidades de emprego. Cabe deixar claro que não se espera que os mapas gerados venham indicar onde estariam localizadas as populações mais empobrecidas ou vulneráveis. Para conseguir identificar essas localizações outros dados devem ser considerados.

Os mapas foram desenvolvidos de forma a indicar 1 (um) ponto para um determinado número de domicílios cujos os responsáveis pelo domicílio possuem a mesma renda. Desta forma é possível perceber a composição de renda dentro de cada setor censitário. Na maioria dos mapas utilizou-se o agrupamento de 50 domicílios por ponto, entretanto conforme a dimensão e densidade do município foram utilizadas outras grandezas com o objetivo de melhor revelar a realidade. Estas variações constam sempre das legendas dos mapas. Cabe ainda dizer que os pontos ficam distribuídos nos setores censitários correspondentes de forma a evitar sobreposições. Por fim vale alertar que as escalas utilizadas variam conforme a dimensão dos municípios de forma a todos caberem em uma folha A0, conforme indicado em cada mapa.

$\mathrm{Na}$ analise comparada dos mapas de renda, desenvolvidos para as cidades mencionadas, foi possível identificar diferentes padrões de distribuição de rendas sobre o território. Interessa-nos saber se os padrões identificados nos indicam aspectos da forma urbana.

Para definição dos padrões identificados adota-se valor de referência o fato da renda ser maior ou menor que três salários mínimos. Justifica-se este critério pelo fato de corresponder a $56 \%$ da população que ganha até 3 salários mínimos. Cabe considerar ainda que é esta faixa de renda que os programas sociais, entre eles o habitacional, têm dificuldades em atender. 
Apresentamos a seguir os sete padrões identificados que possuem entre si diferentes características na distribuição espacial da renda sobre seu território:

Padrão 1 - Municípios de grandes dimensões, onde a área urbana é uma pequena parcela de seu território;

Padrão 2 - Municípios onde os responsáveis pelos domićlios com rendas acima de 3 salários mínimos estão concentrados em uma localidade;

Padrão 3 - Municípios onde os responsáveis pelos domicílios com rendas acima de 3 salários mínimos estão concentrados ao longo de uma linha ou vetor;

Padrão 4 - Municípios onde os responsáveis pelos domicílios com rendas acima de 3 salários mínimos estão concentrados em setores longe dos centros tradicionais;

Padrão 5 - Municípios onde os responsáveis pelos domicílios com rendas de até 3 salários mínimos são preponderantes;

Padrão 6 - Municípios com duas concentrações de distintas faixas de renda: um com predominância de até 3 salários mínimos e outro com predominância de rendas de mais de 3 salários mínimos dos responsáveis pelos domicílios;

Padrão 7 - Municípios onde os responsáveis pelos domicílios com rendas acima de 3 salários mínimos são preponderantes e presentes em todo território urbano.

Adotou-se a seguinte legenda para a indicação das faixas de renda:

Até um salário mínimo

$\bigcirc$ De um a três salários mínimos

De três a cinco salários mínimos

De cinco a dez salários mínimos

Acima de dez salários mínimos 
Figura 2: Padrão 1, Municípios de grandes dimensões - Campo Grande/MS; Manaus/AM; Macapá/AP; Rio Branco/AC. Fonte: Jonathas Magalhães Pereira da Silva, 2016.

\section{Padrão 1 - Municípios de grandes dimensões}

Os municípios que possuem um grande território municipal com pequenas e médias áreas urbanas foram identificados como um padrão. Justifica-se esta escolha por conta dos dados municipais terem de considerar as grandezas das dimensões territoriais para compreender direito cada contexto.

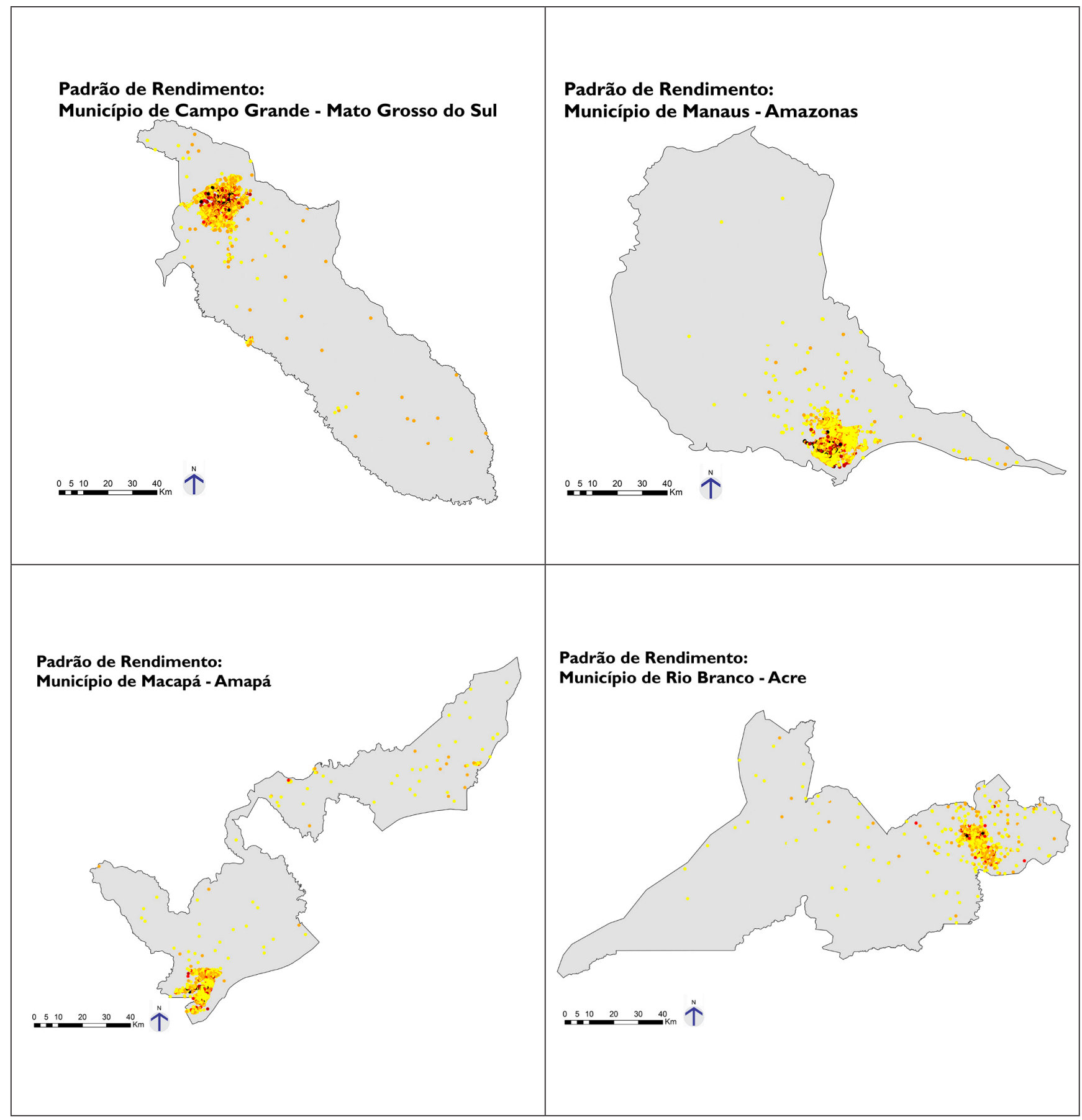


Figura 3a: Padrão 2 - Belo Horizonte/MG; Recife/PN. Fonte: Jonathas Magalhães Pereira da Silva, 2016.

\section{Padrão 2 - Municípios onde os responsáveis pelos domicílios com rendas acima de 3 salários mínimos estão concentrados em uma localidade}

É o tipo de distribuição mais esperado em uma sociedade com grandes concentrações de renda e forte segregação sócio-espacial. As médias e altas rendas se encontram localizados de forma concentradas em pontos específicos da cidade. A localização dos melhores empregos, e consequentemente melhores rendas dos responsáveis, parecem estar associados às áreas de maior renda domiciliar per capta, este é o caso de Belo Horizonte/MG; Recife/PN; Campo Grande/MS; Goiania/GO, Salvador/BA, Brasíli/BR, Vitória/ES, Maceió/AL.
Padrão de Rendimento: Belo Horizonte/MG

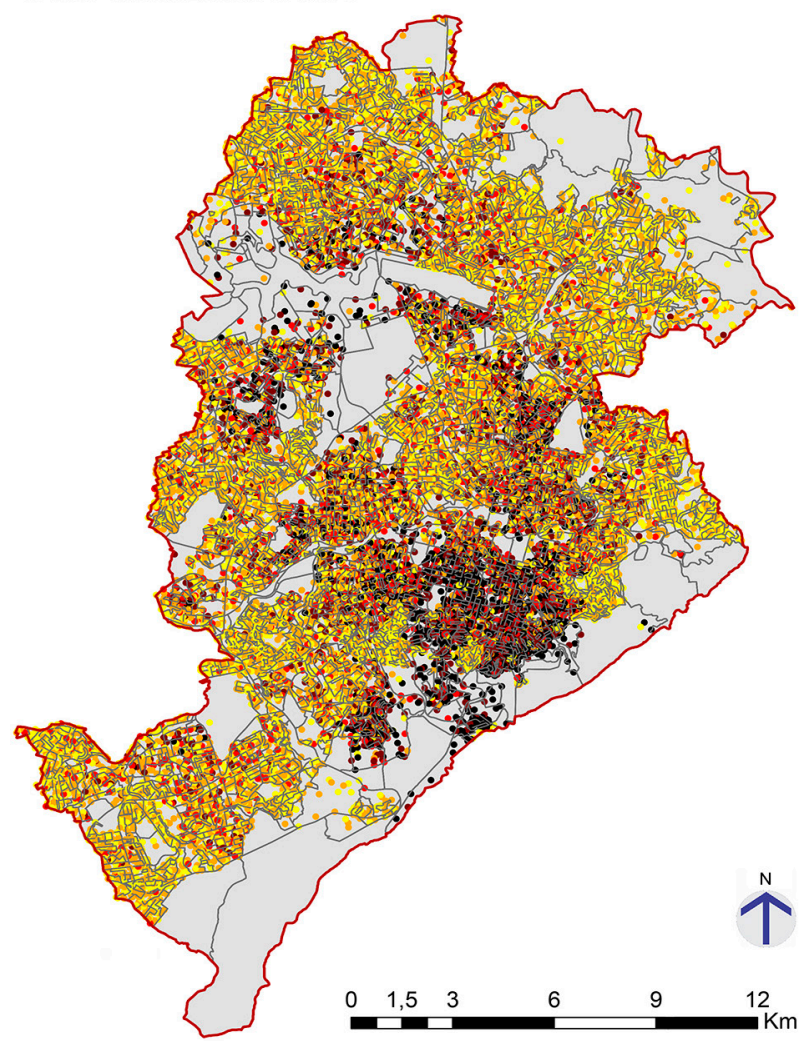

\section{Padrão de Rendimento:} Recife/PE

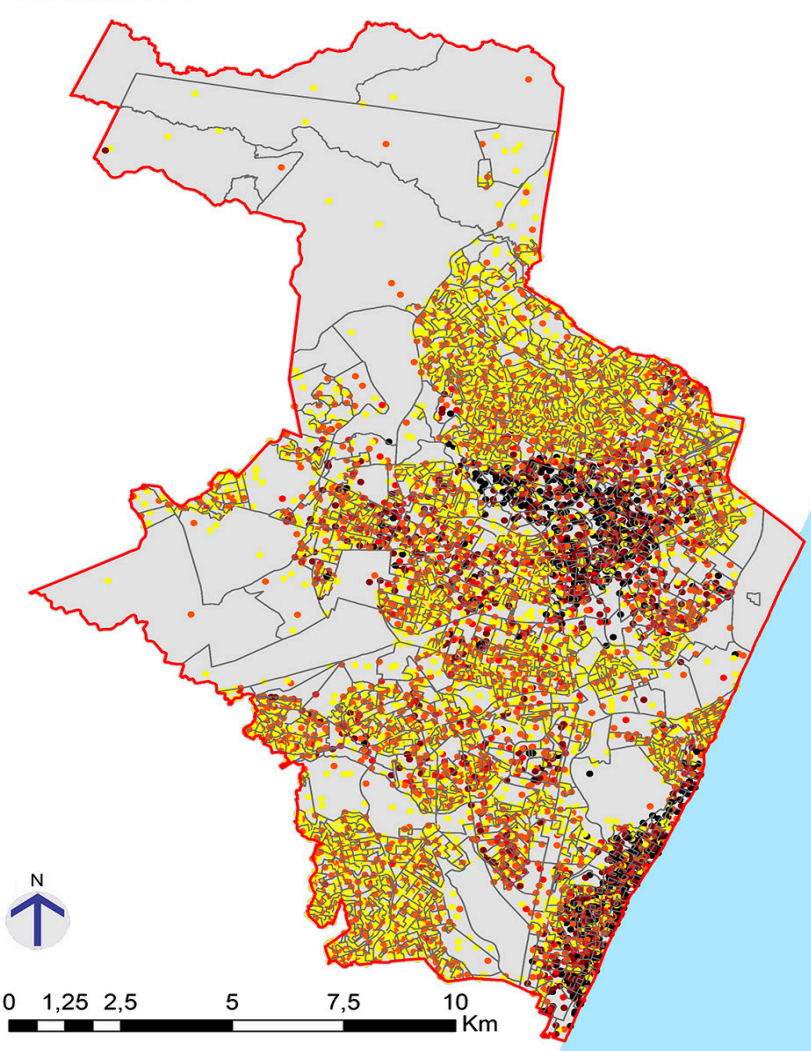




\section{Padrão de Rendimento:}

Campina Grande - PB

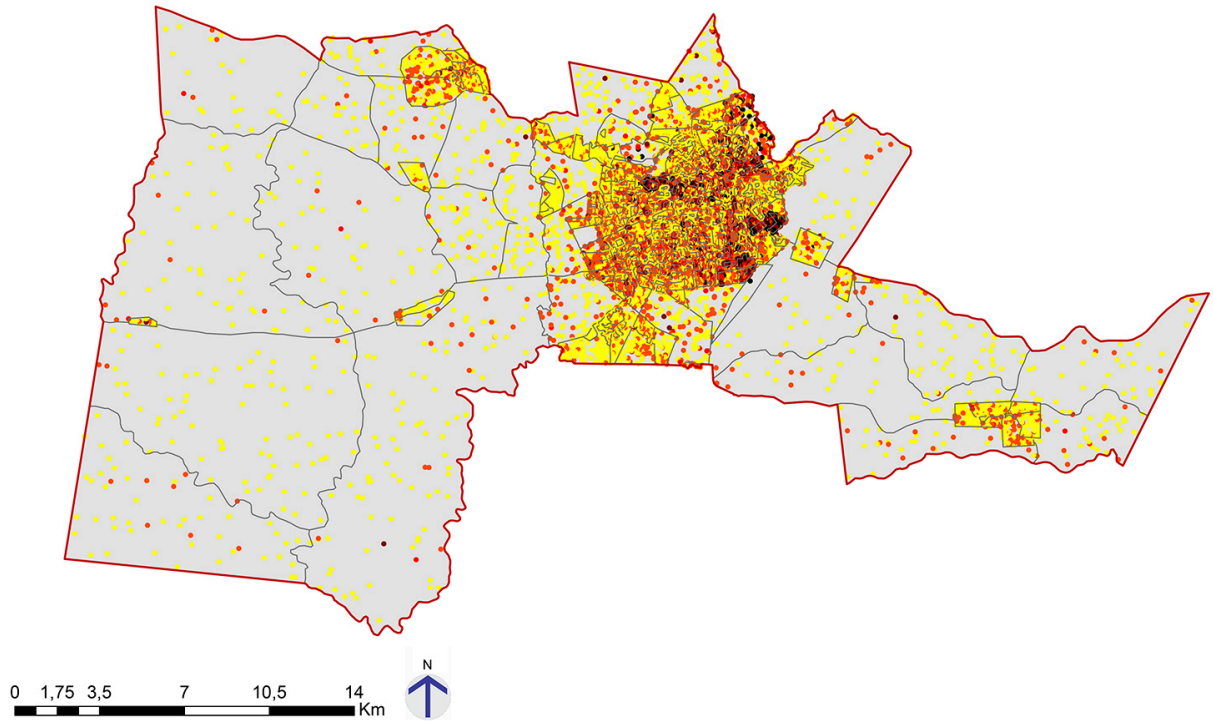

Padrão de Rendimento:

Município de Brasília - Distrito Federal

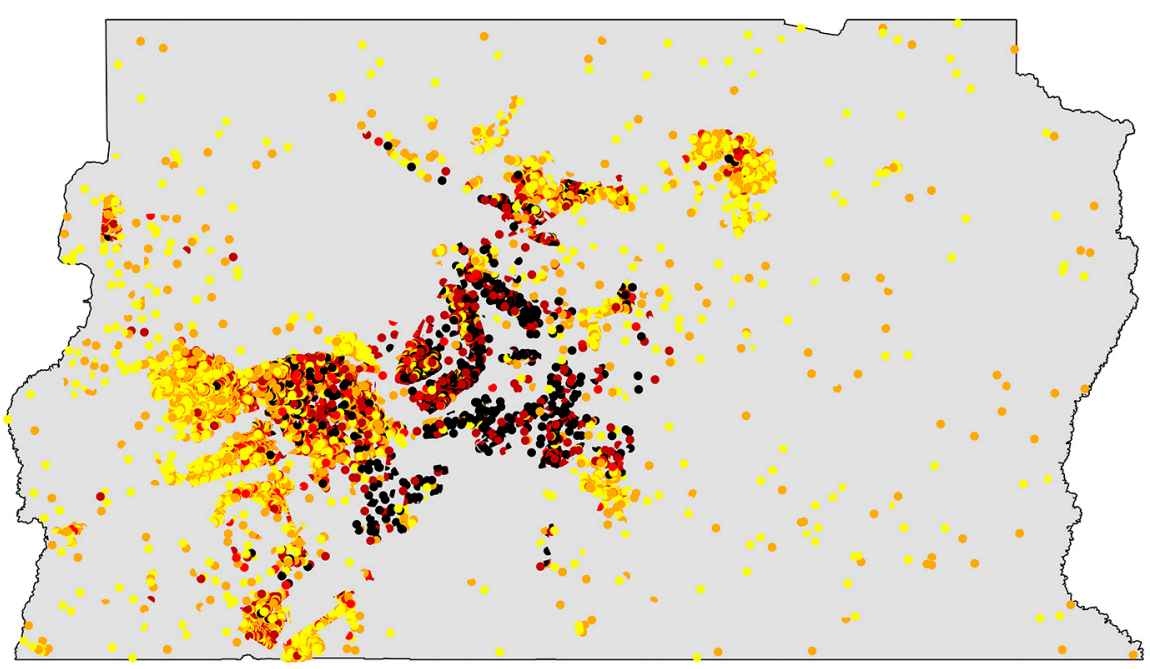

Figura 3b: Padrão 2 - Campo

Grande/MS; Goiania/GO. Fonte: Jonathas Magalhães Pereira da Silva, 2016. 


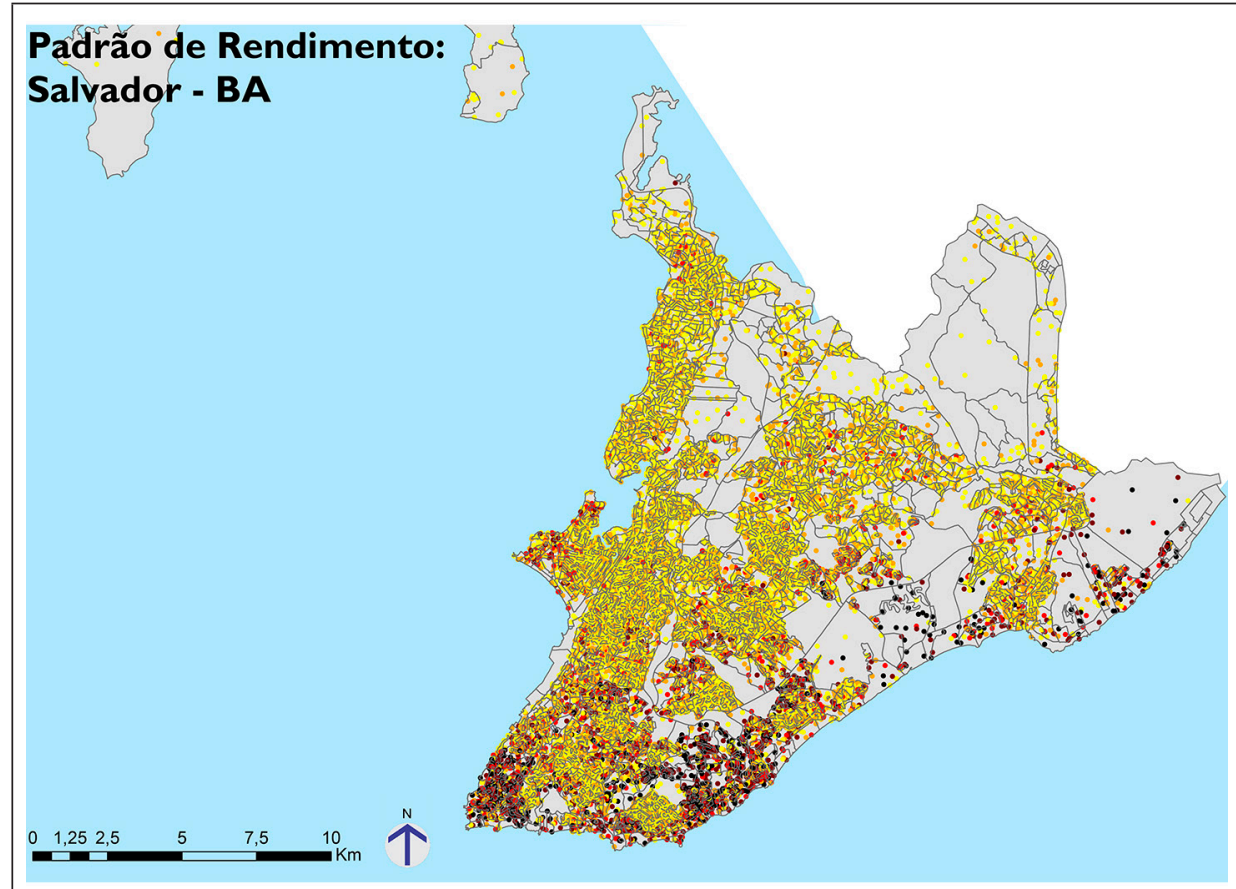

Padrão de Rendimento:

Município de Brasília - Distrito Federal

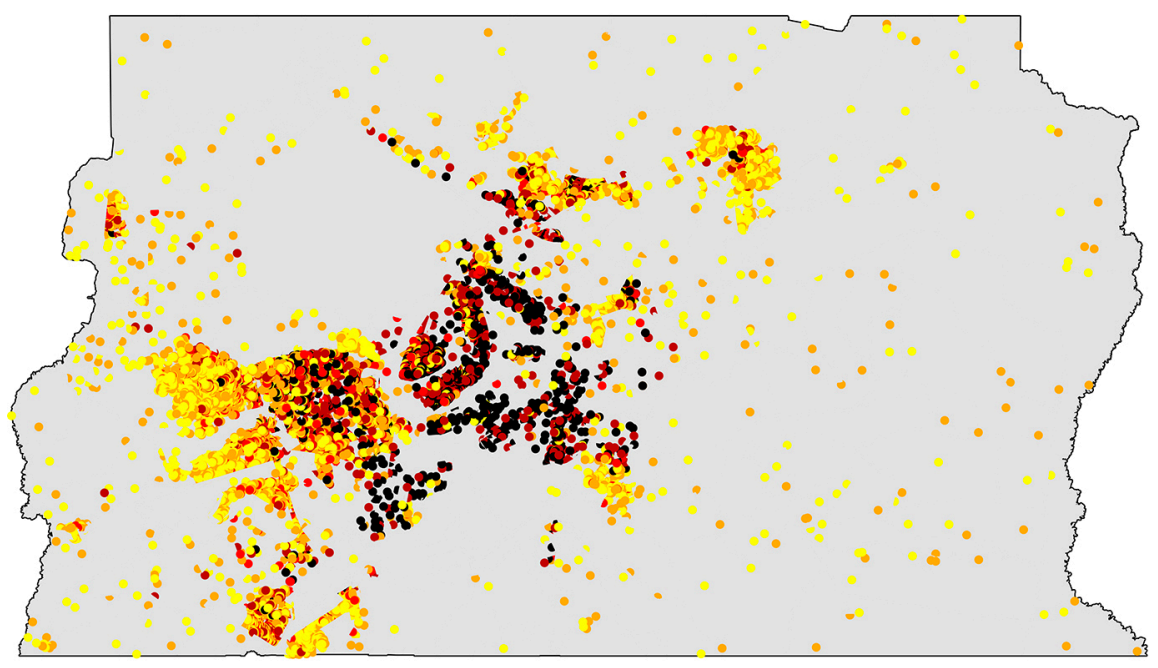




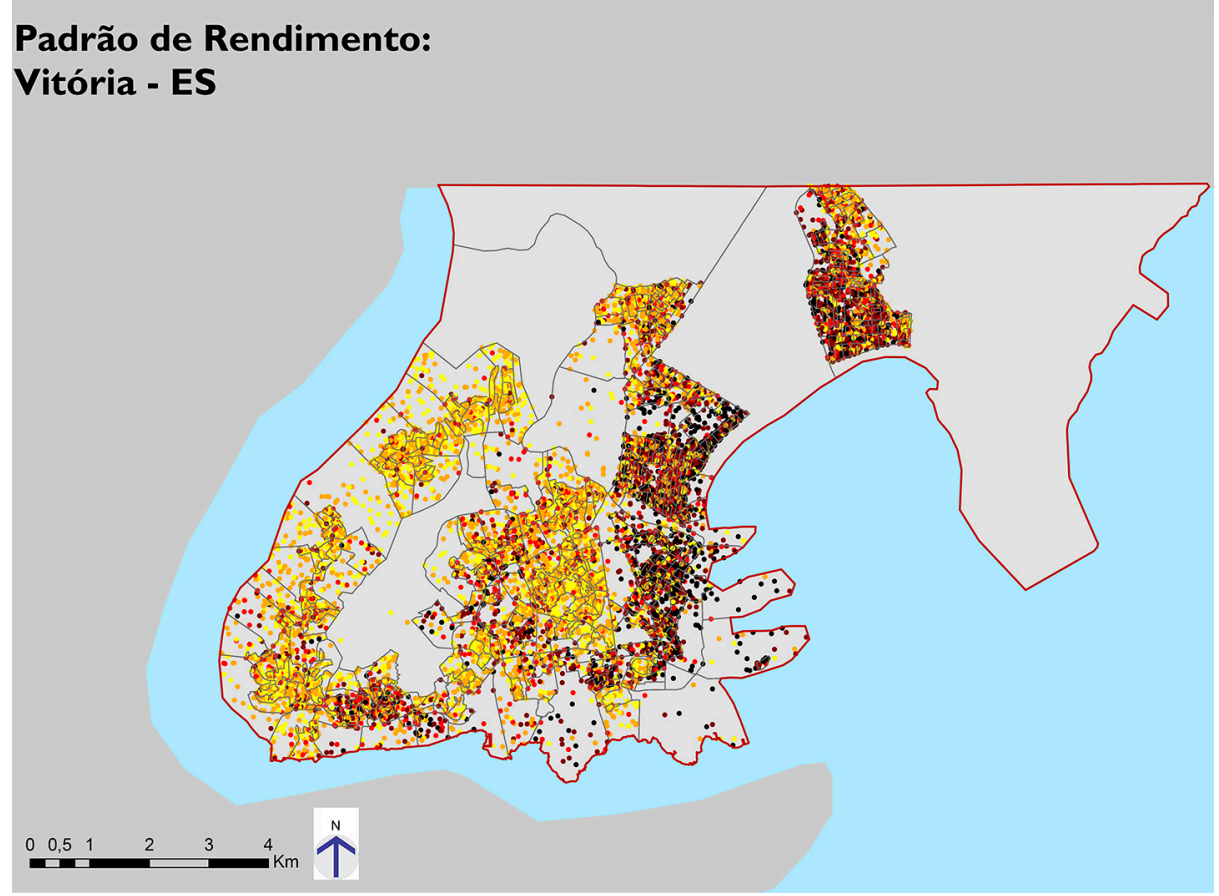

\section{Padrão de Rendimento:} Maceió - AL
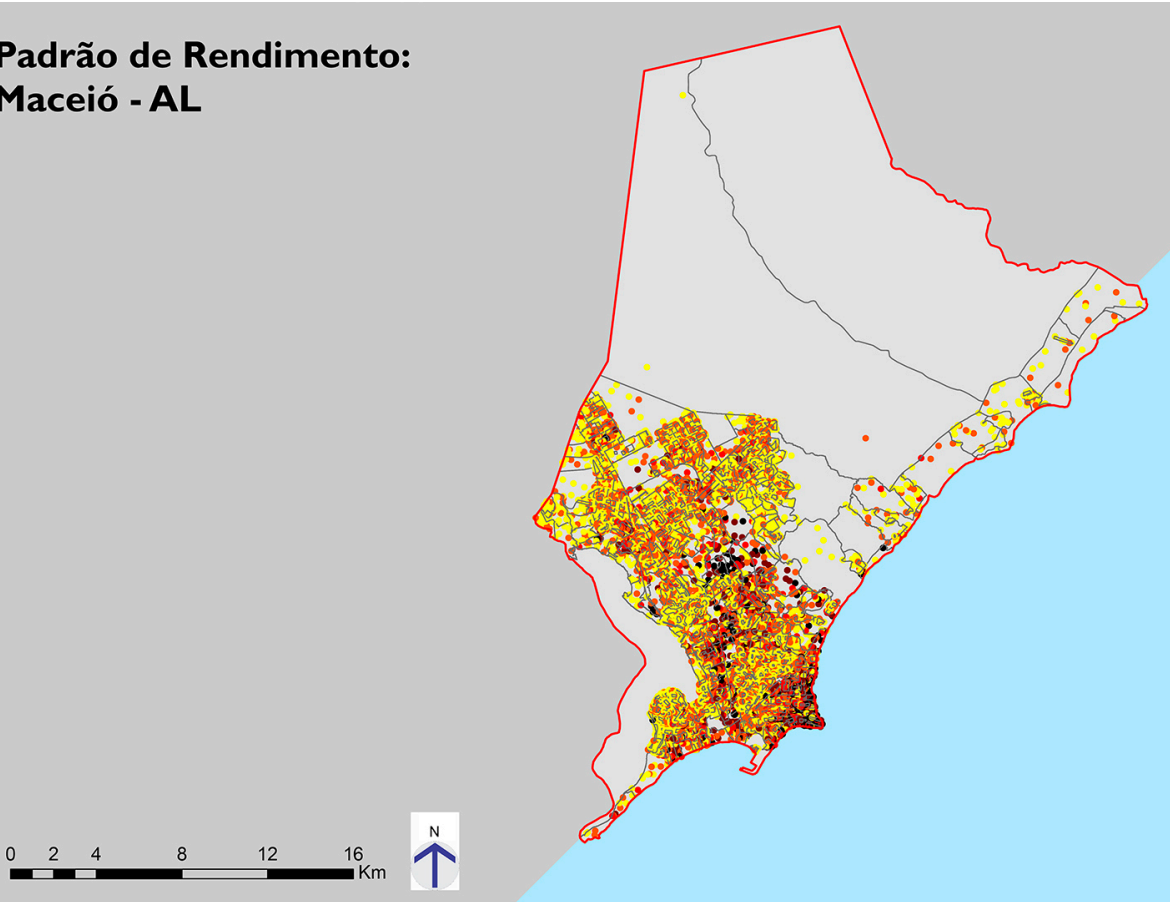

Figura 3d: Padrão 2 - Vitória/ 
Figura 4a: Padrão 3 - Campinas/ SP; Rio de Janeiro/RJ. Fonte: Jonathas Magalhães Pereira da Silva, 2016.

\section{Padrão 3 - Municípios onde os responsáveis pelos domicílios com rendas acima de 3 salários mínimos estão concentrados ao longo de uma linha ou vetor}

Os municípios do Rio de Janeiro /RJ; Natal /RN; São Luiz /MA; João Pessoa /PB e Fortaleza/CE têm como característica comum terem um vetor onde se concentram as médias e altas rendas das pessoas responsáveis pelos domicílios. No caso Região Metropolitana de Campinas - SP as médias e altas rendas das pessoas responsáveis parecem estar associados às áreas de maior renda per capta em função do domicílio sem necessariamente estar relacionado a oferta de empregos de maiores rendas no local de residência.
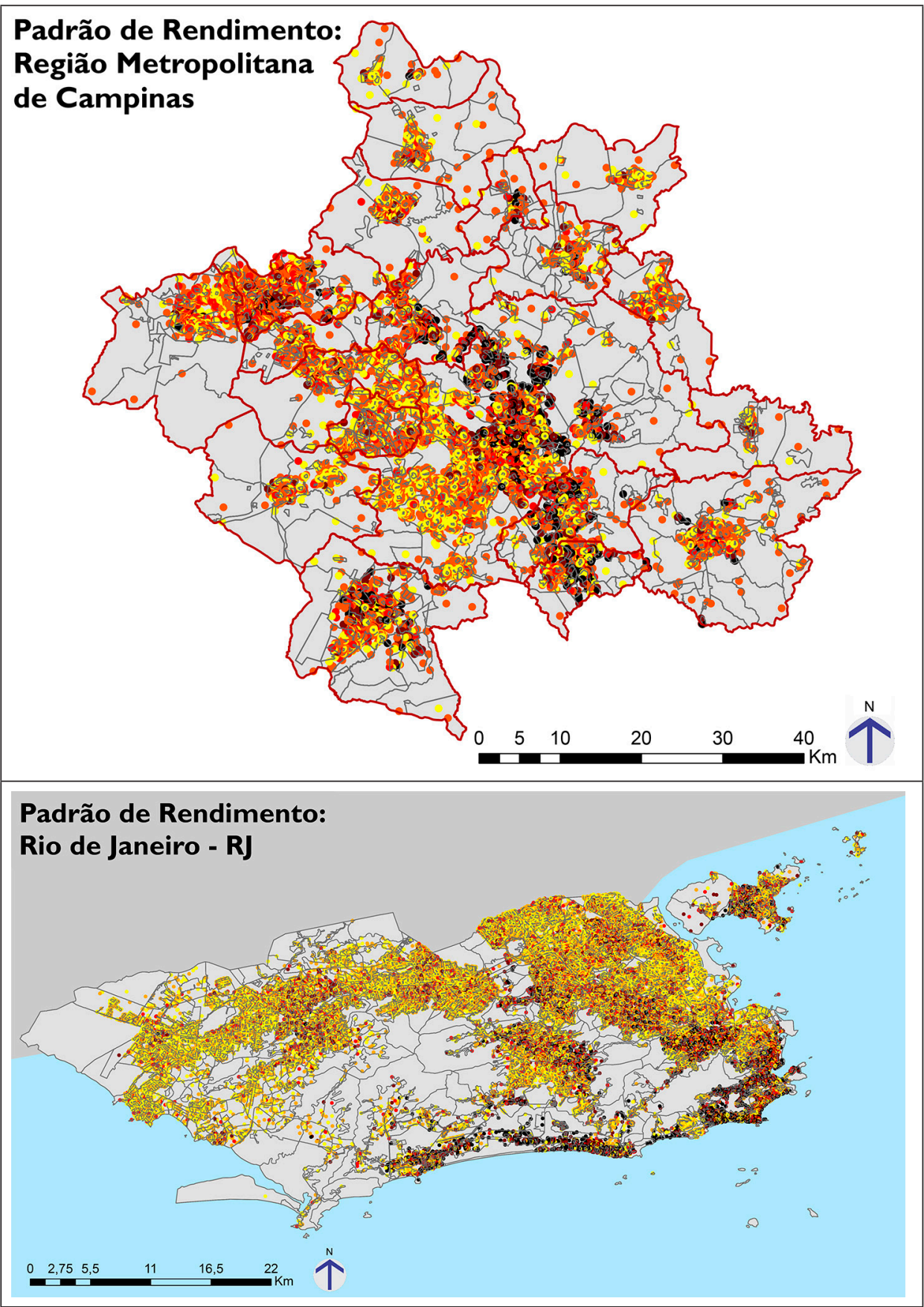


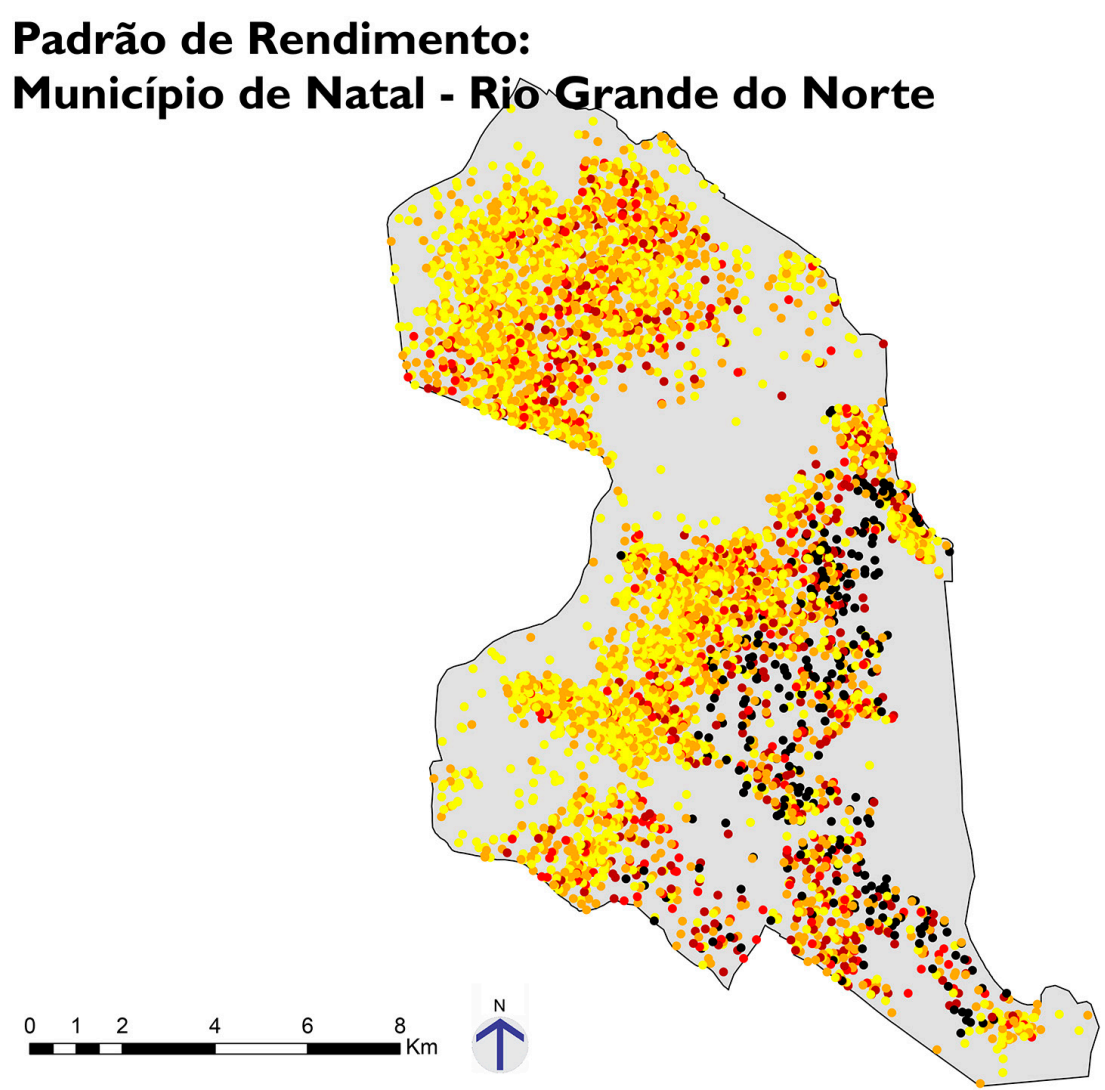

\section{Padrão de Rendimento:}

Município de São Luís - Maranhão

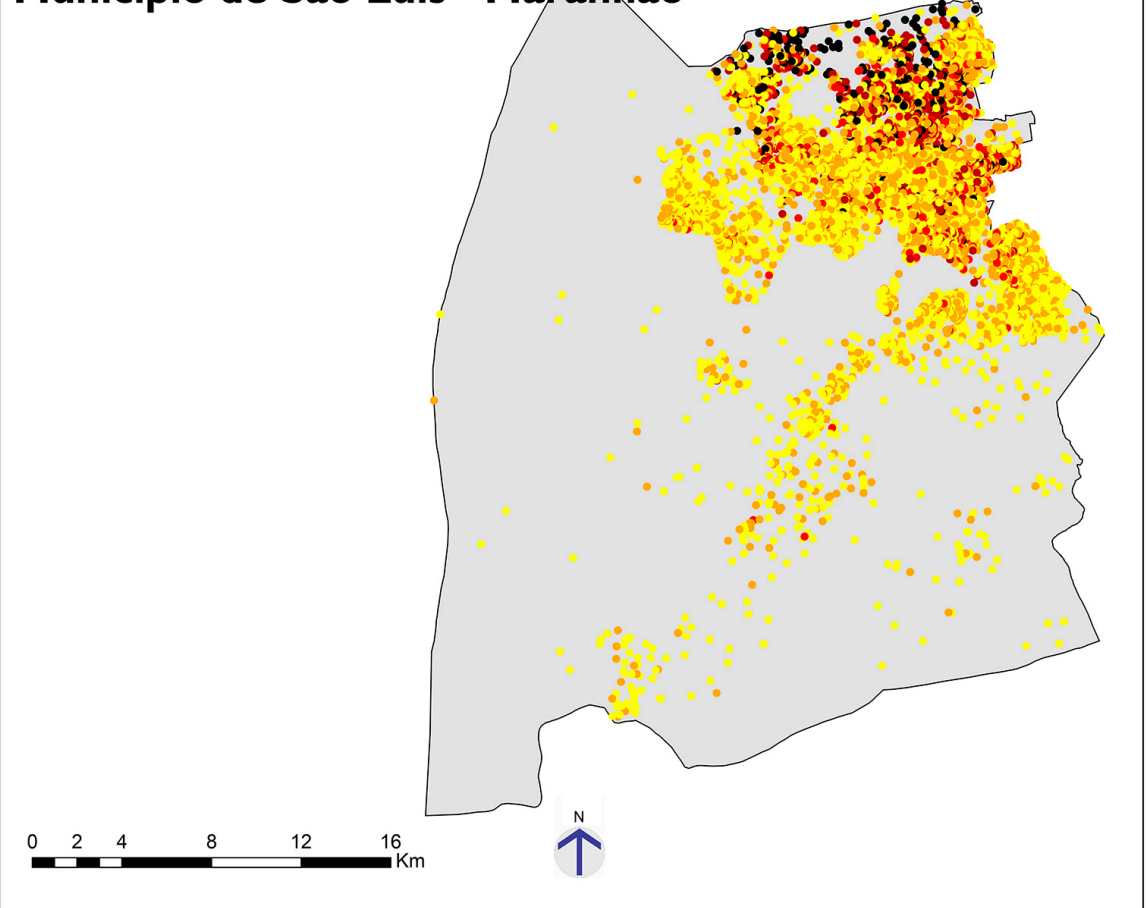




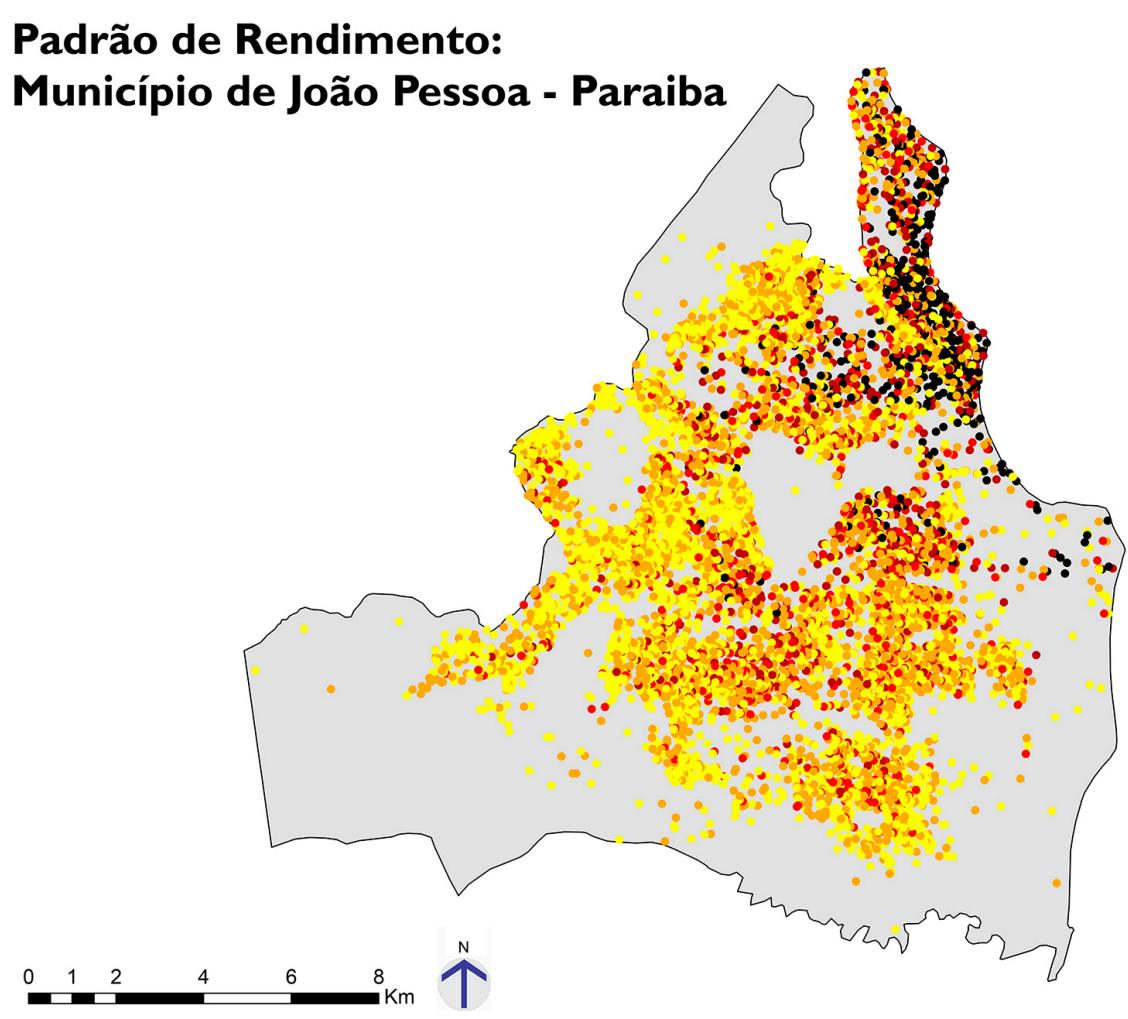

\section{Padrão de Rendimento:}

Município de Fortaleza - Ceará

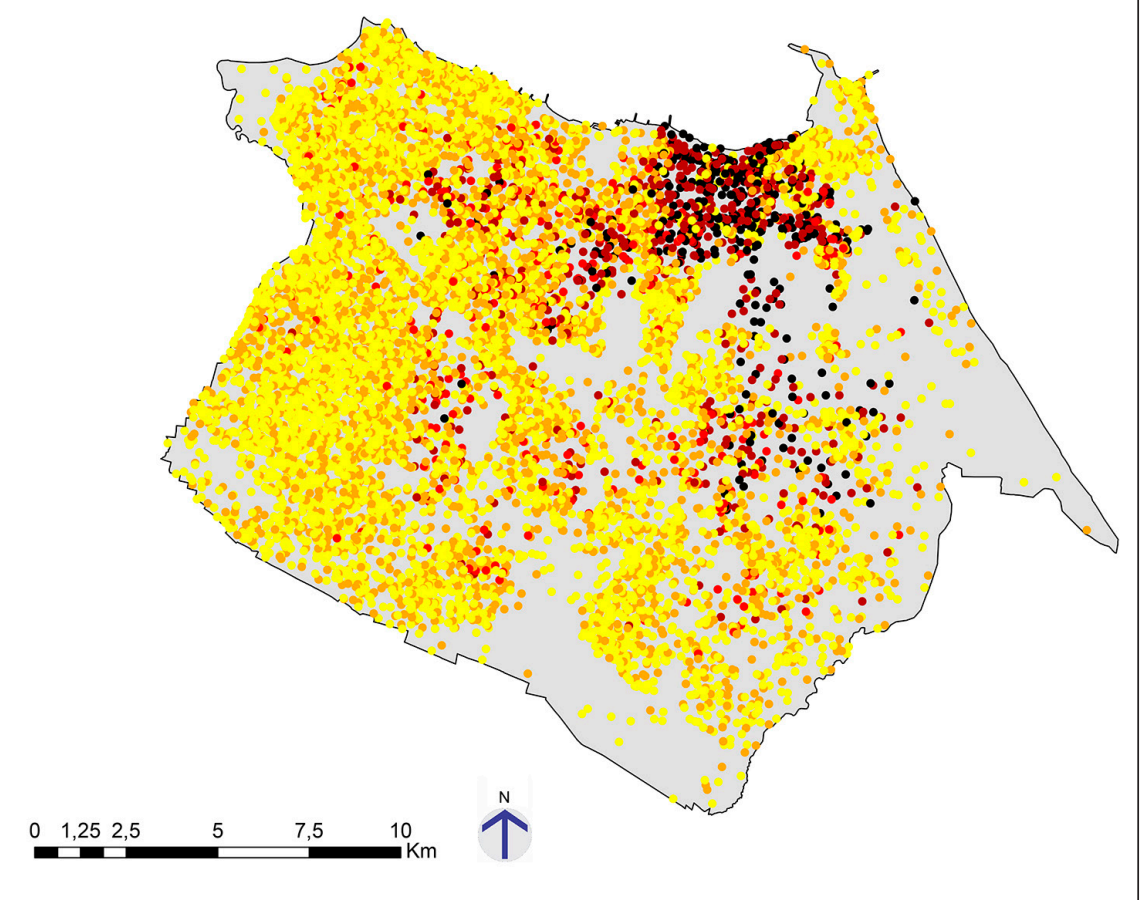

Figura 4c: Padrão 3 - João Pessoa/PB e Fortaleza/CE. Fonte: Jonathas Magalhães Pereira da Silva, 2016. 
Figura 5: Padrão 4 - Uberlândia/ MG; São Carlos/SP e Sorocaba/ SP. Fonte: Jonathas Magalhães Pereira da Silva, 2016.
Padrão 4 - Municípios onde os responsáveis pelos domicílios com rendas acima de 3 salários mínimos estão concentrados em setores longe dos centros tradicionais

É o caso de municípios como Uberlândia/MG, São Carlos/SP e Sorocaba/SP onde as médias e altas rendas das pessoas responsáveis pelos domicílios localizam-se nas bordas da área urbana.

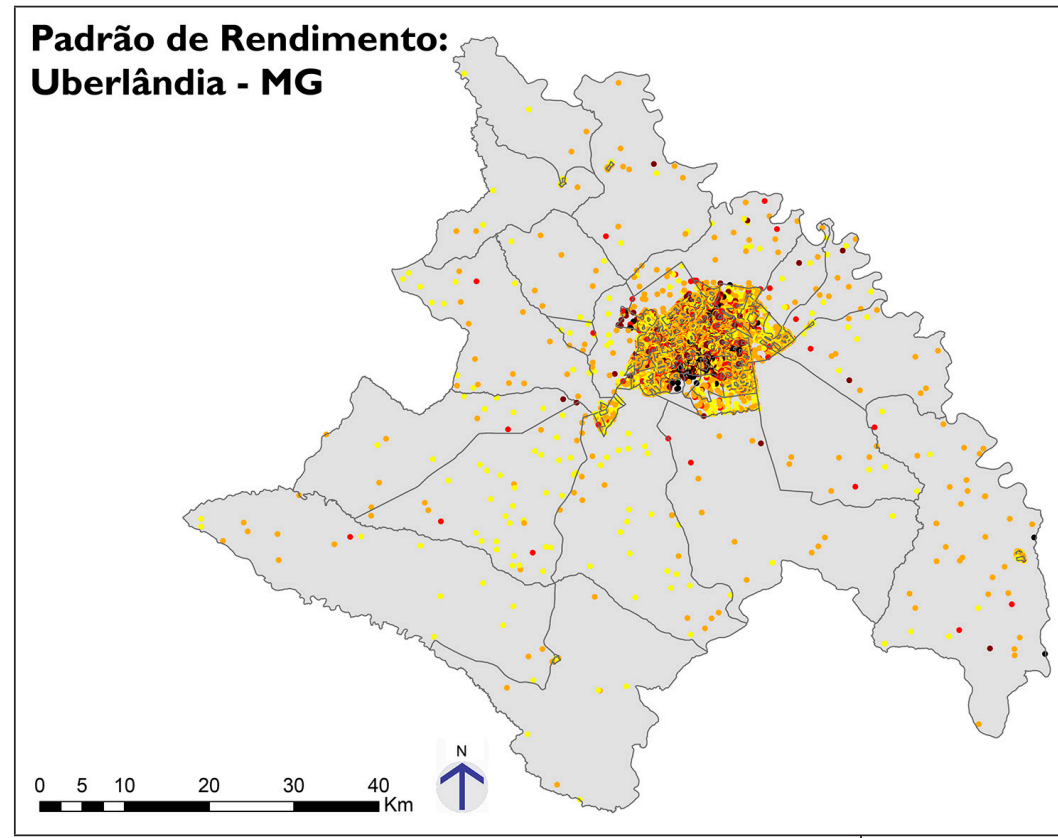

Padrão de Rendimento:

São Carlos - SP

Padrão de Rendimento:

Sorocaba - SP

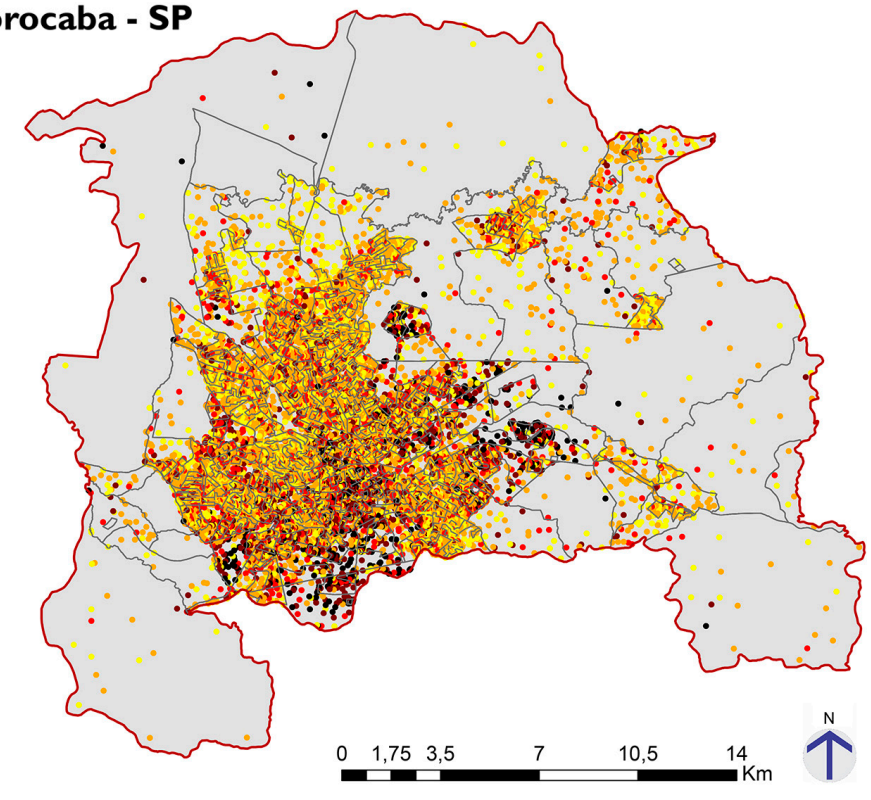

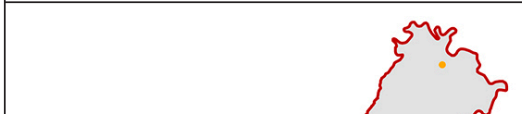

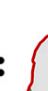
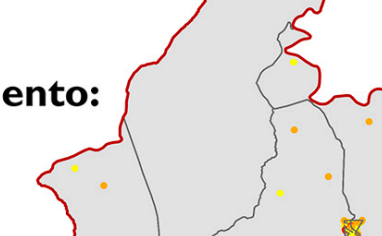
Figura 6a: Padrão 5 - Região Metropolitana da Baixada Santista/SP; Ampliação com Santos e Guarujá/SP. Fonte: Jonathas Magalhães Pereira da Silva, 2016.

\section{Padrão 5 - Municípios onde os responsáveis pelos domicílios com rendas de até 3 salários mínimos são preponderantes}

São exemplos desse padrão os municípios contidos na região metropolitana da Baixada Santista/SP, Uberaba/MG e Santa Maria/RS onde os responsáveis pelos domicílios com rendas de até 3 salários mínimos são preponderantes sobre o território sem haver uma concentração significativa de responsáveis de domicílios com altas rendas. No caso da Região metropolitanas da Baixada Santista, quando aproximamos a analise para os municípios de Santos e Guarujá a concentração acima de 5 salários mínimos são ainda bastante pontuais.
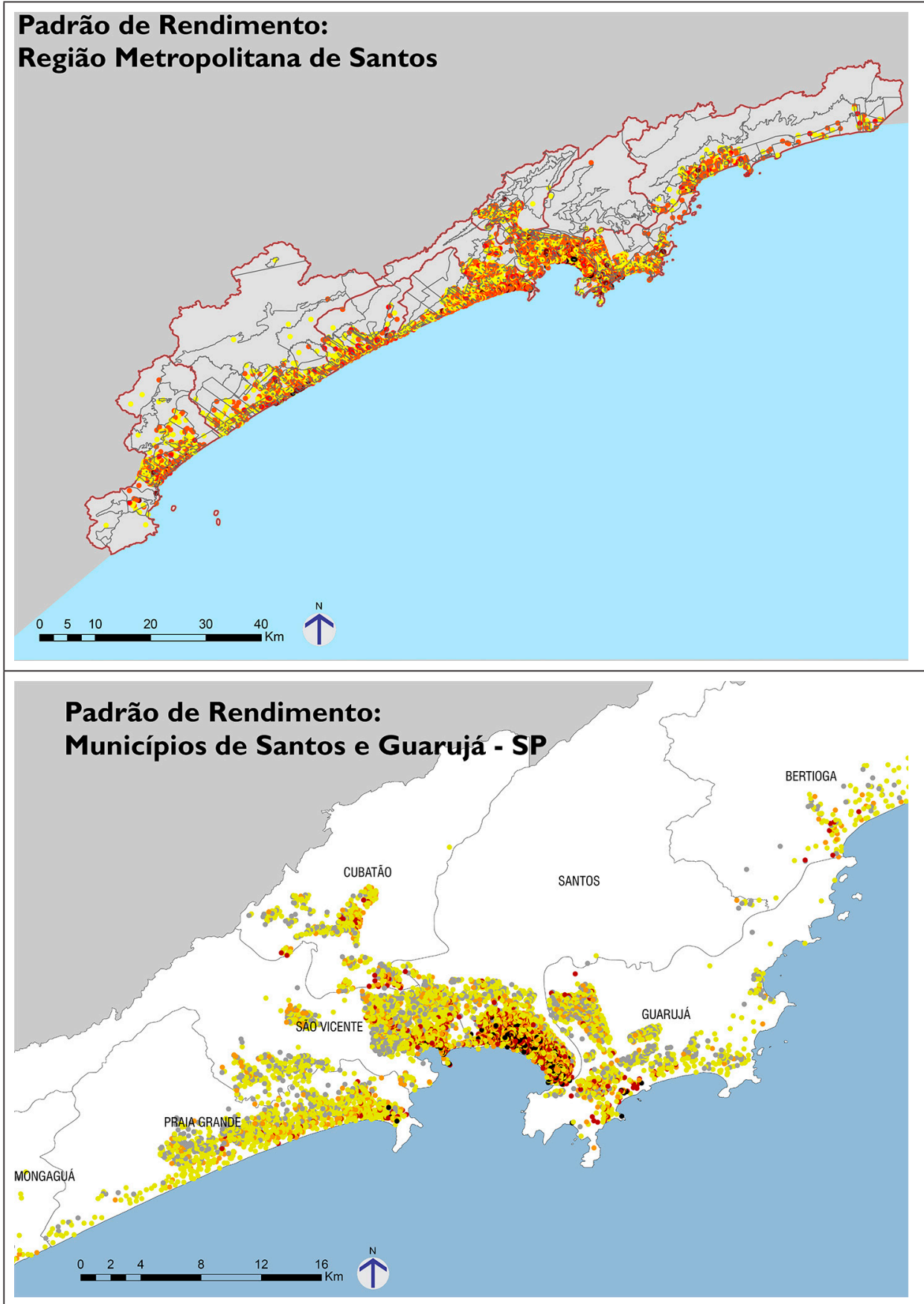


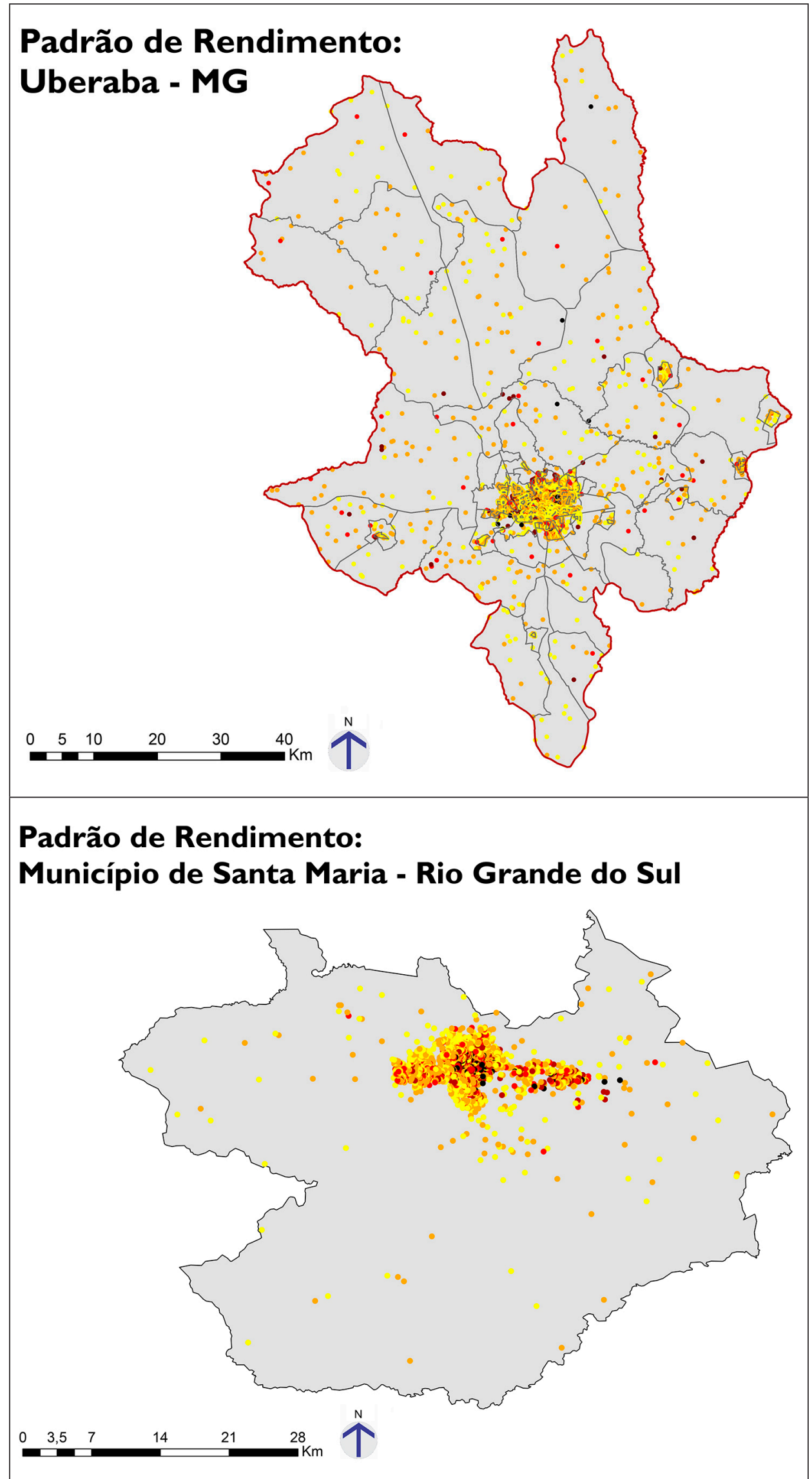

Figura 6b: Padrão 5 - Uberaba/ MG e Santa Maria/RS. Fonte: Jonathas Magalhães Pereira da Silva, 2016.

Padrão de Rendimento:

Município de Santa Maria - Rio Grande do Sul 
Figura 7: Palmas/TO; Belém/PA. Fonte: Jonathas Magalhães Pereira da Silva, 2016.
Padrão 6 - Municípios com duas concentrações de distintas faixas de renda: um com predominância de até 3 salários mínimos e outro com predominância de rendas de mais de 3 salários mínimos dos responsáveis pelos domicílios

São exemplos os Municípios de Palmas/TO e Belém/PA se destacam dos demais pela existência de duas áreas que se diferenciam pelos padrões de renda. Enquanto Palmas tem uma concentração de rendas, acima de 5 salários mínimos, de responsáveis por domicílio na área pertencente ao plano original da cidade, observa-se ao sul, fora da área planejada, a concentração de rendas abaixo de 5 salários mínimos. Já no município de Belém as altas e médias rendas são concentradas mais próximas às áreas centrais enquanto ao norte a concentração de renda até 3 salários mínimos é predominante.

Deve-se considerar que diferentemente de Palmas a região norte de Belém é uma região de veraneio (ilha do mosqueiro) da elite local. Neste caso a presença predominante de baixa renda se justificam por se tratar de segunda residência. O resultado obtido pode ser explicado pela ocasião da coleta de dados do IBGE não ter coincidido com período de veraneio, desta forma os dados coletados foram dos moradores do local que tem suas baixas rendas associadas a serviços prestados aos proprietários desta localidade. Destaca-se aqui este fato para alertar, conforme salientado no início da análise, que os mapas de renda não caracterizam por si as áreas precárias da cidade.

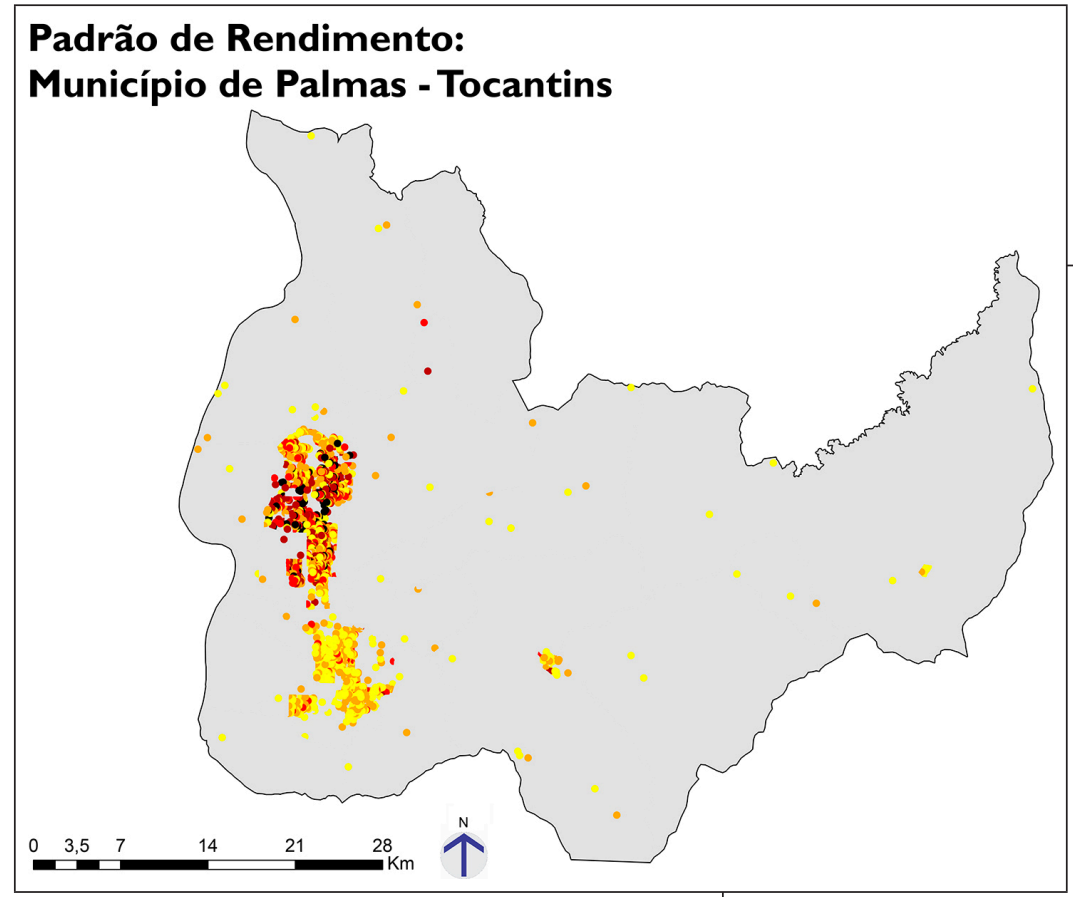

Padrão de Rendimento: Município de Belém - Pará
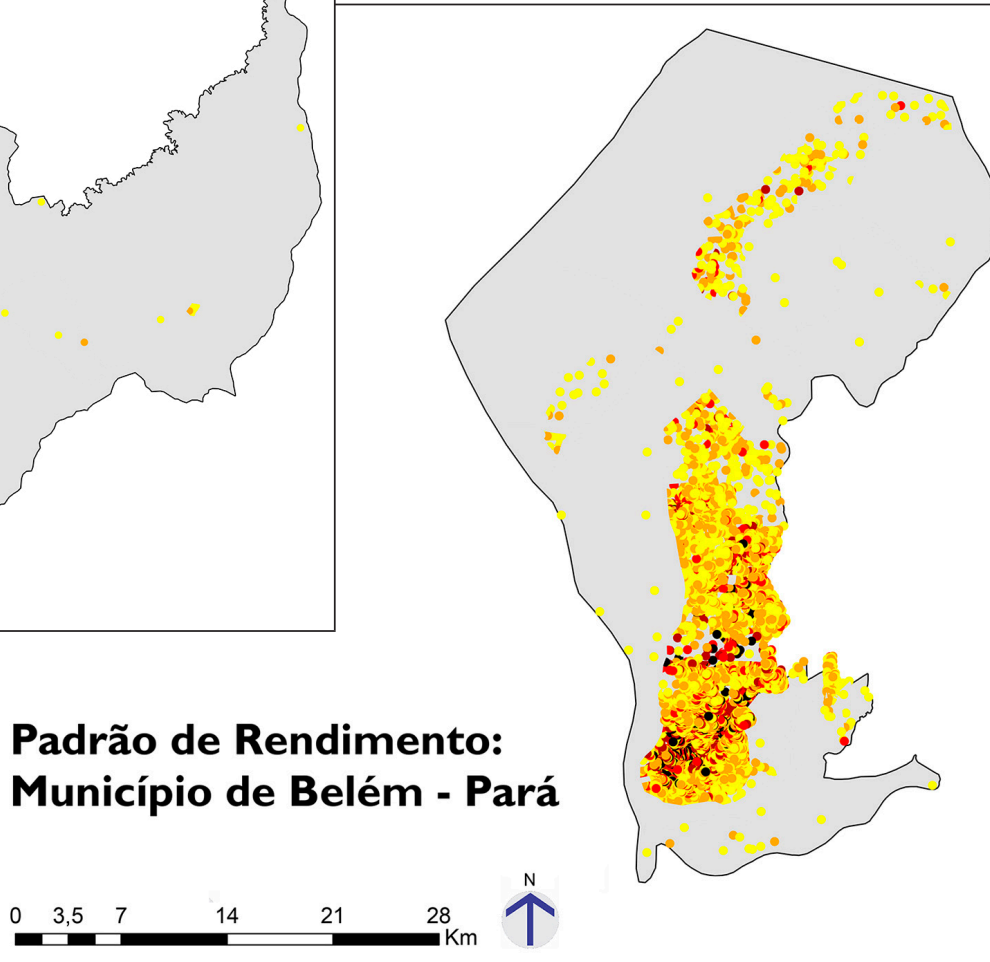
Figura 8a: Padrão7 - Curitiba/ PR; Maringa/PR. Fonte: Jonathas Magalhães Pereira da Silva, 2016.
Padrão 7 - Municípios onde os responsáveis pelos domicílios com rendas acima de 3 salários mínimos são preponderantes e presentes em todo território urbano

Dos sete padrões identificados, este foi o que mais nos gerou estranheza, pois nos mapas de renda das pessoas responsáveis pelos domicílios dos municípios de: Curitiba/PR; Maringa/PR; Florianópolis/SC e Criciúma/SP existe uma distribuição de rendas acima de 3 salários por todo o território municipal, havendo ainda uma redução sensível de incidência de rendas abaixo de 3 salários mínimos (amarelos e laranjas).

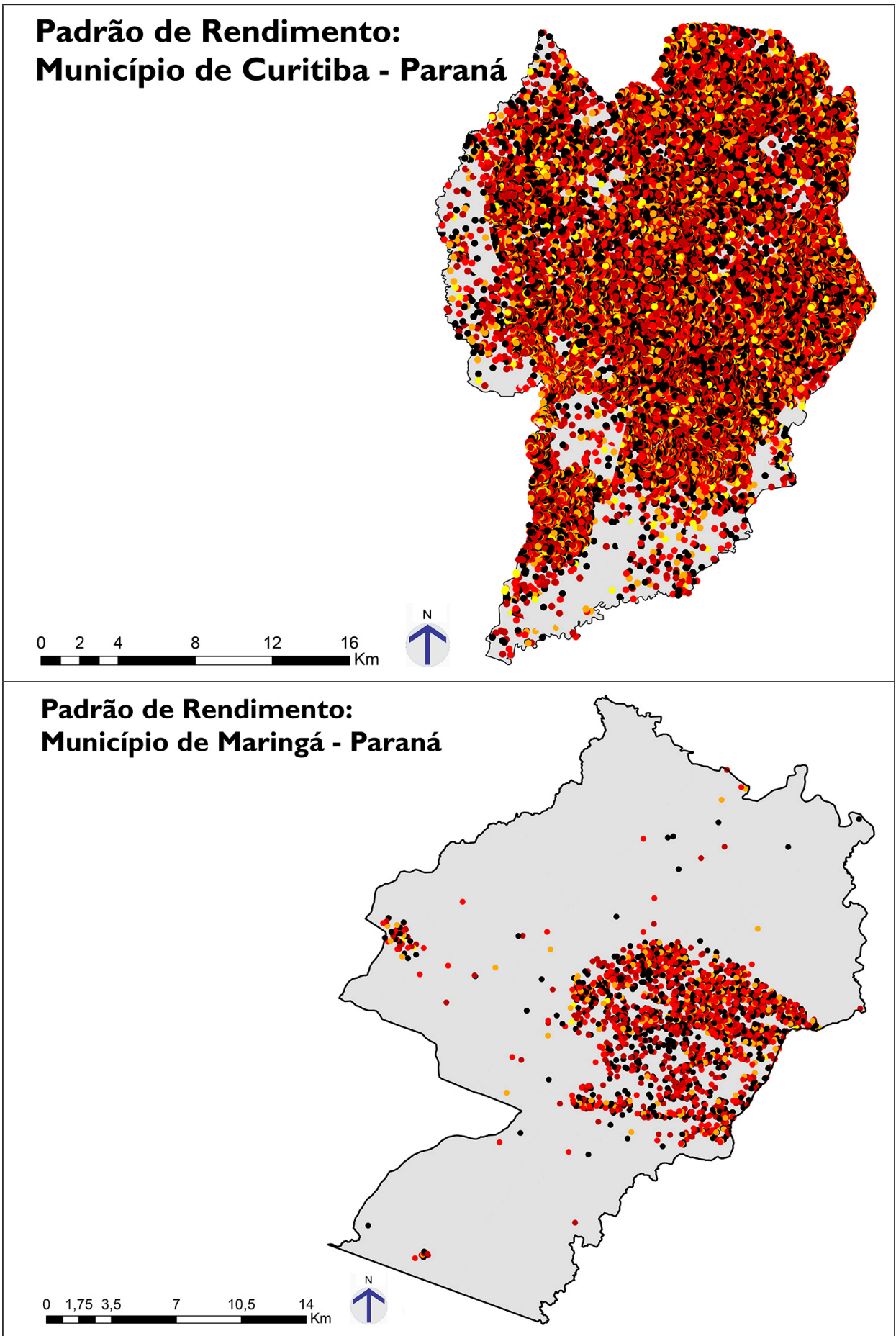




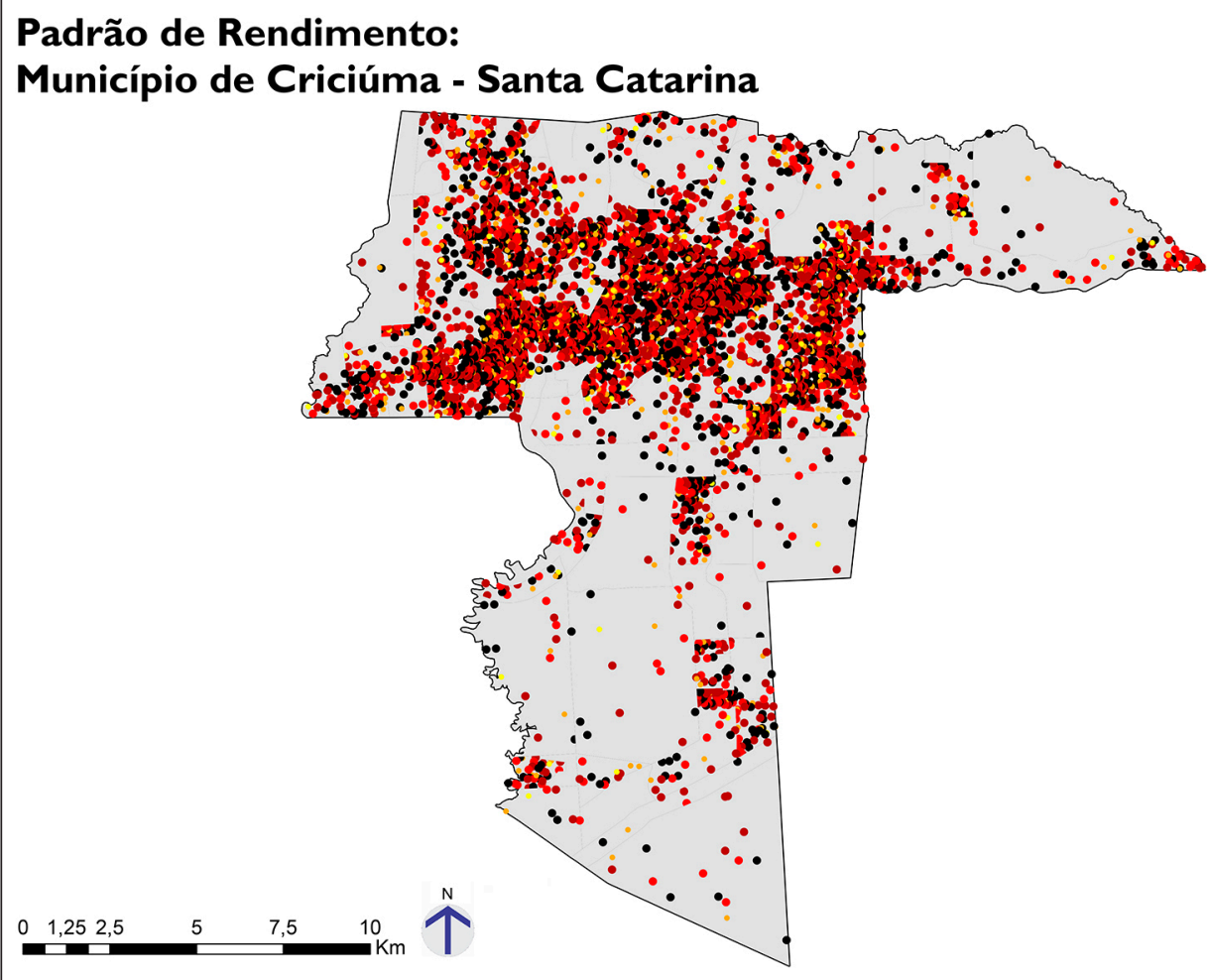

\section{Padrão de Rendimento:}

Município de Florianópolis - Santa Catarina

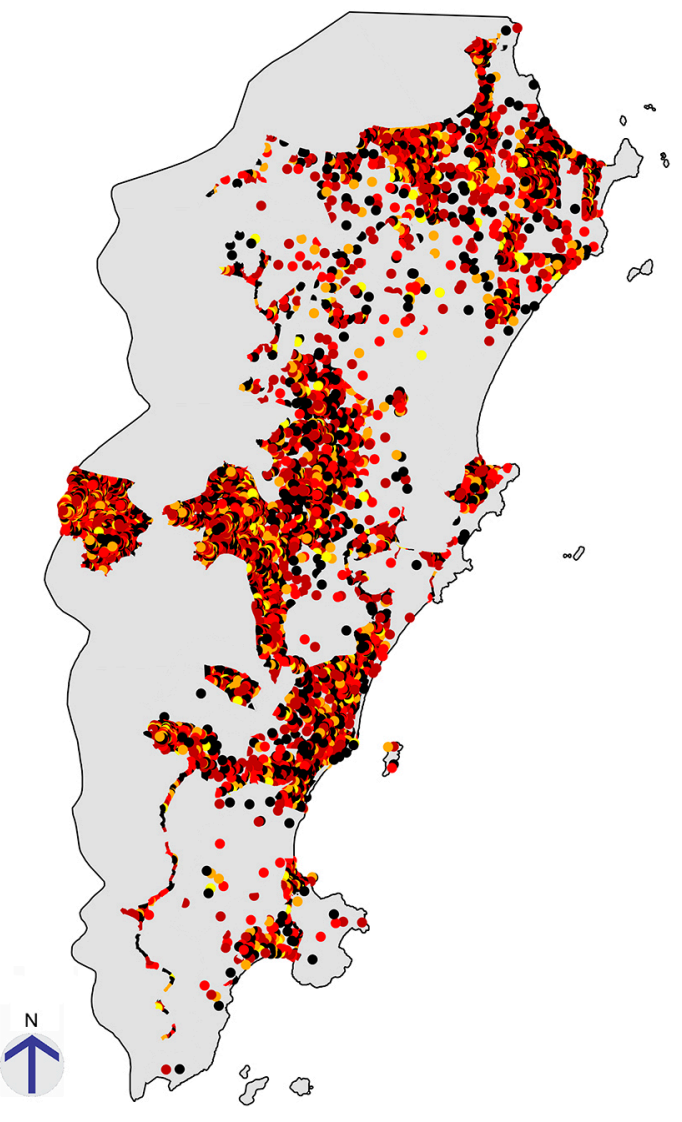


Figura 9: Curitiba e municípios do entorno/PR; mapa por renda da pessoa responsável do domicílio; um ponto representa 50 domicílios. Fonte: Jonathas Magalhães Pereira da Silva, 2017.
Na tentativa de investigar mais este inesperado padrão identificado tomou-se o município de Curitiba para fazer algumas averiguações. Curitiba é enaltecida como cidade diferenciada pela estruturação de sua mobilidade e simultaneamente duramente criticada por diferentes autores em função do processo de segregação socioespacial (OLIVEIRA, 2000; SANCHEZ, 1997; SOUZA, 1999). Partiu-se, portanto, do pressuposto que o processo de segregação promovido pelo planejamento do município de Curitiba, já bastante estudado, teria induzido a fixação, nos municípios do entorno, de responsáveis por domicílio com menores renda. Entretanto ao desenvolver o mapa da região metropolitana de Curitiba as baixas rendas não se destacaram.

\section{Padrão de Rendimento: Região Metropolitana de Curitiba}

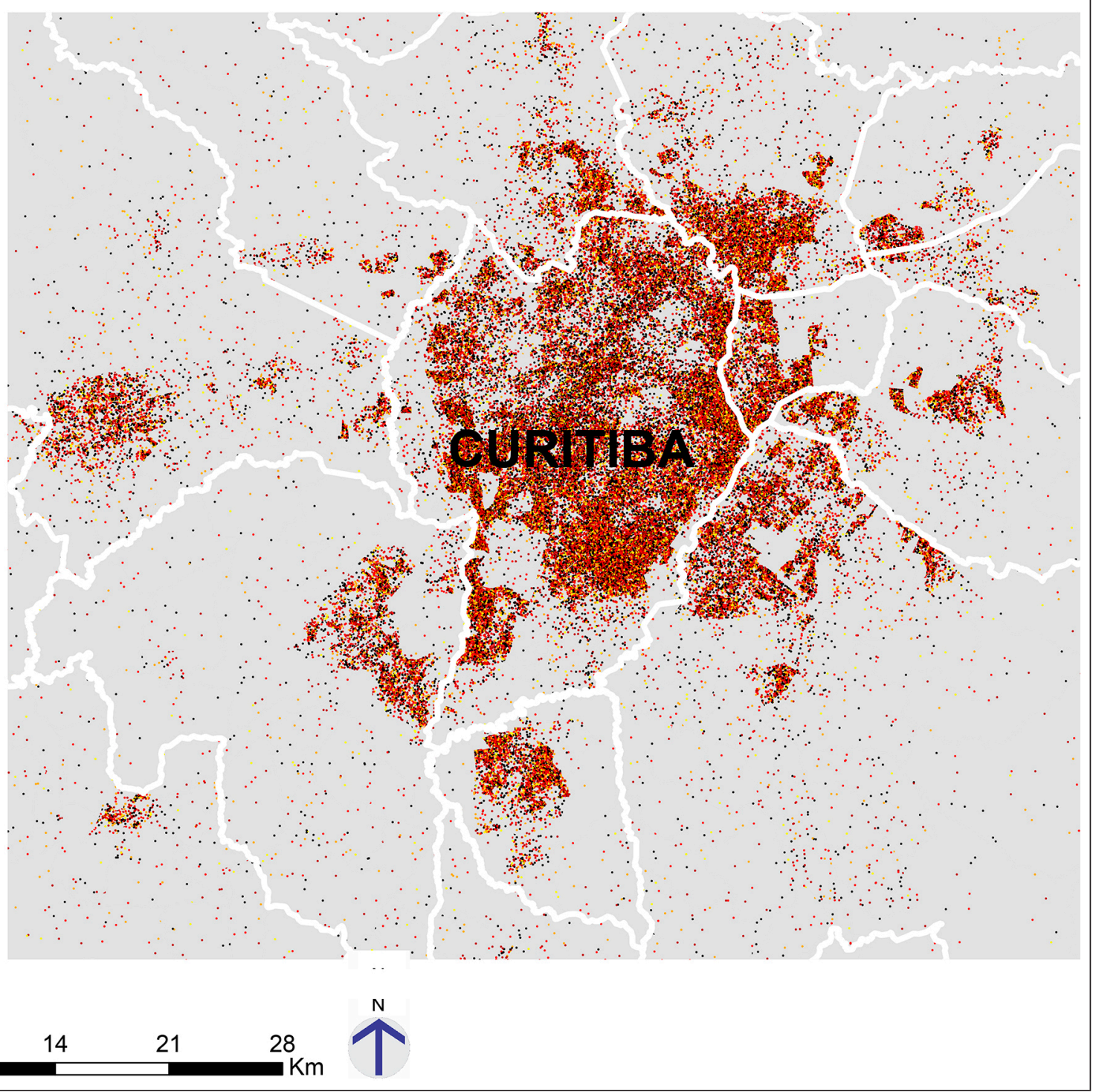




\section{Padrão de Rendimento: Região Metropolitana de Curitiba}
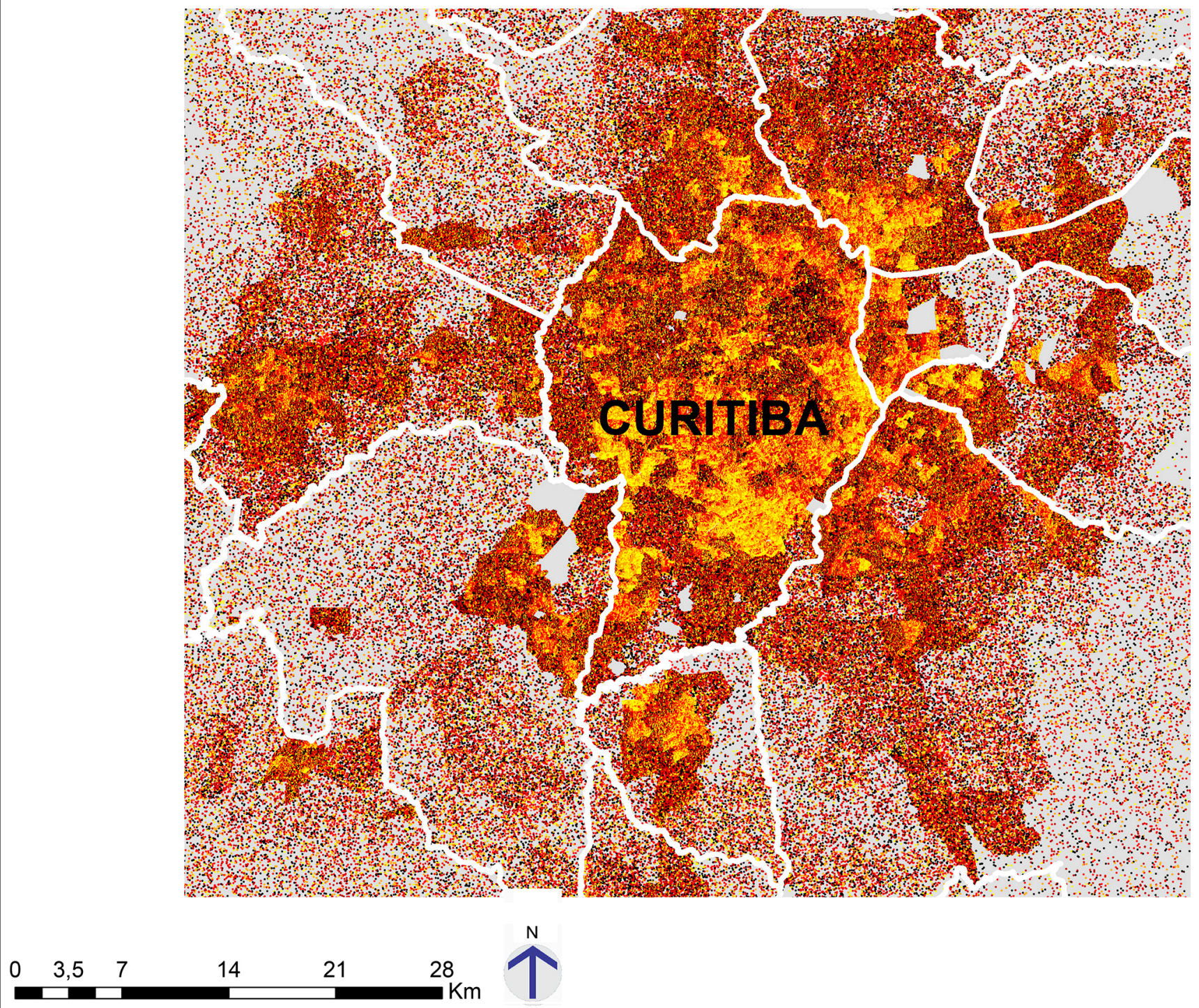

Figura 10: Curitiba e municípios do entorno/PR; mapa por renda da pessoa responsável do domicílio; um ponto representa 1 domicílio. Fonte: Jonathas Magalhães Pereira da Silva, 2017
Resolvemos então aumentar a precisão do mapa tornando cada ponto um único responsáveis por domicílio, desta forma mesmo que em menor número, as rendas abaixo de 3 salários mínimos seriam percebidas. Entretanto uma nova questão surge com o resultado obtido. As menores rendas das pessoas responsáveis pelos domicílios se concentram no centro da região metropolitana estando predominantemente no município de Curitiba. Qual a explicação? Analises sobre as diferentes rendas de Curitiba demonstram e justificam a presença de baixas rendas no município (CARVALHO, 2014). 
Figura 11: Curitiba e municípios do entorno/PR; mapa por renda média do domicílio per capta; um ponto representa 1 domicílio. Fonte: Jonathas Magalhães Pereira da Silva, 2017.
De fato, se ao invés de se tomar os dados do responsável se desenvolvesse o mapa de renda utilizando a tabela de "renda média per capta do domicílio" confirmam-se as análises de Carvalho, mas não respondem a razão do padrão identificado ao usar os dados dos "responsáveis do domicílio". Como colocado no inicio do texto não trazemos no presente artigo respostas e sim questionamentos. O que significa esse padrão predominante por todo o território metropolitano de Curitiba indicando que grande maioria das pessoas responsáveis de domicílios tem rendas médias acima de 5 salários mínimos?

Considerando que outras cidades brasileiras apresentam padrões bastante distintos e que se aproximam de mapas de renda que utilizam a tabela de "renda média per capta do domicílio", como é o caso de Recife (Figura 12).

\section{Padrão de Rendimento:} Região Metropolitana de Curitiba
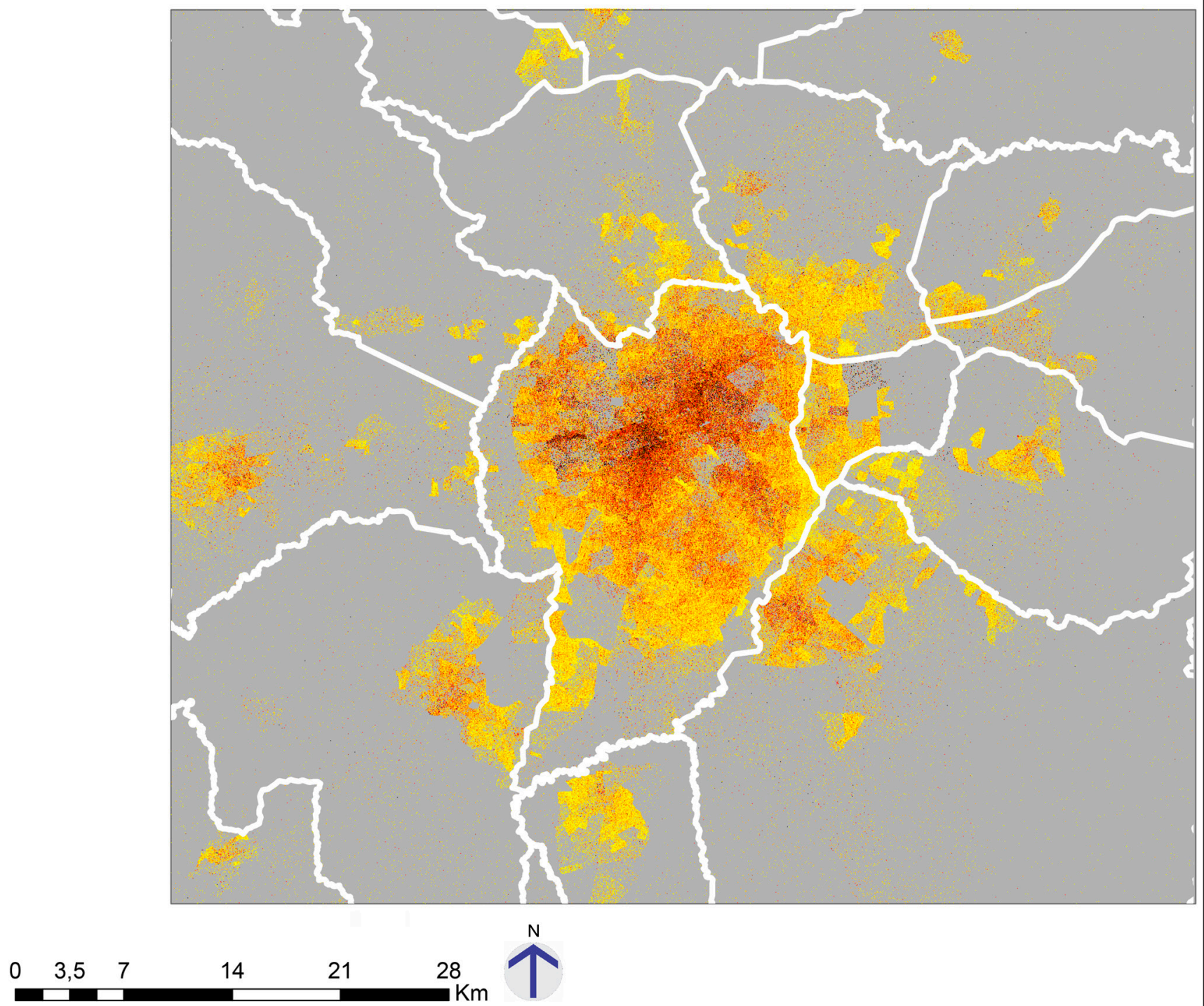


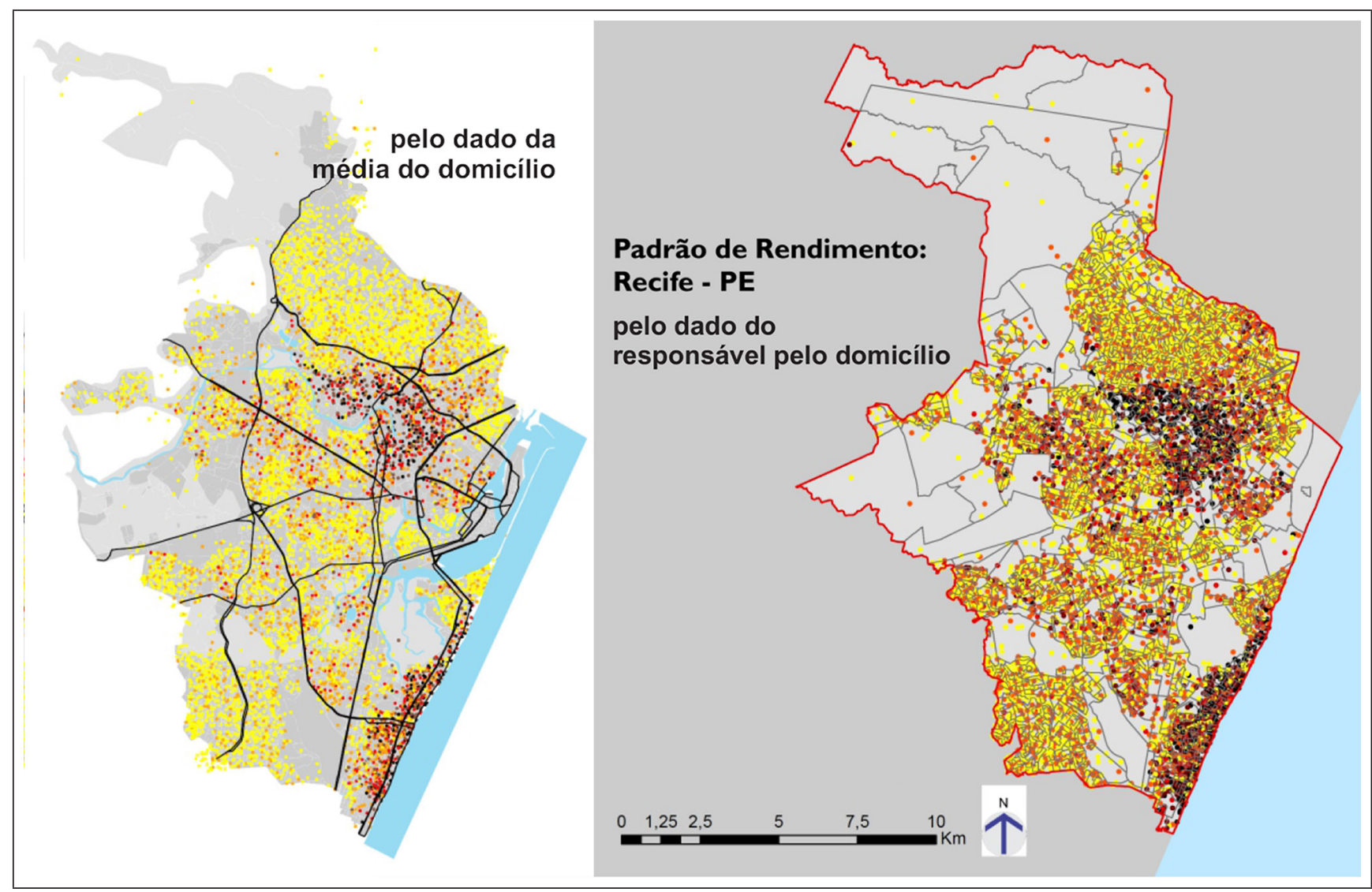

Figura 12: Recife/PE; mapa por renda média do domicílio per capta (esquerda) e mapa por renda da pessoa responsável do domicílio (direita); um ponto representa 50 domicílios. Fonte: Jonathas Magalhães Pereira da Silva, 2016.
Temos duas hipóteses iniciais possíveis: a) a coleta de dados deste item em algumas cidades não foi precisa gerando erros; b) de fato existe um padrão de distribuiç̧ão de renda para o responsável por domicílio que é uniforme no território. A primeira hipótese não se descarta mas é bastante improvável frente ao esforço do IBGE em homogeneizar os dados. Seria mais provável termos uma dificuldade de interpretação destes dados. Caso consideremos a segunda hipótese a o padrão de renda da pessoa responsável do domicílio seria diluída ou potencializada na medida em que existe, ou não, oportunidades de rendas, para os demais membros do domicílio. Estas oportunidades estariam ligadas as condições de inserção urbana das diferentes localidades? As condições locais resultam em diferentes formas urbanas? Existe alguma relação entre estes padrões de renda e a forma urbana?

\section{Renda e Forma urbana}

No presente artigo não cabe relacionar cada um dos padrões de renda com os aspectos morfológicos. Portanto sem querer esgotar o assunto, mas sim lançar questões ao grupo de pesquisa e pesquisadores interessados no tema, passamos a analisar de forma bastante preliminar três estudos de caso: Brasília, Salvador e Recife que pertencem Padrão 2. 
Figura 13: Aspecto Morfológico (esquerda); Aspectos demográficos (Centro); Mapa de Renda por responsáveis de domicílio (direita); Legenda do mapa de aspectos morfológicos de Recife. Fontes: Jonathas Magalhães Pereira da Silva e acervo do grupo de pesquisa, 2016.

\section{Comparamos aqui três mapas:}

1- Mapa de "Aspectos Morfológicos" que tem legendas específicas para os padrões encontrados em cada cidade.

2 - Mapa de "Aspectos Demográficos", desenvolvido a partir da tabela de renda média domiciliar per capta.

3 - Mapa de renda das pessoas responsáveis de domicílios desenvolvido a partir da tabela disponibilizada pelo IBGE : ResponsavelRenda_UF.xls.

No caso de Recife as maiores rendas têm localização coincidente com as quadras verticalizadas que no caso deste município são compostas por torres com mais de 30 andares. As menores rendas têm localização coincidente com edificações horizontais de pequeno porte.

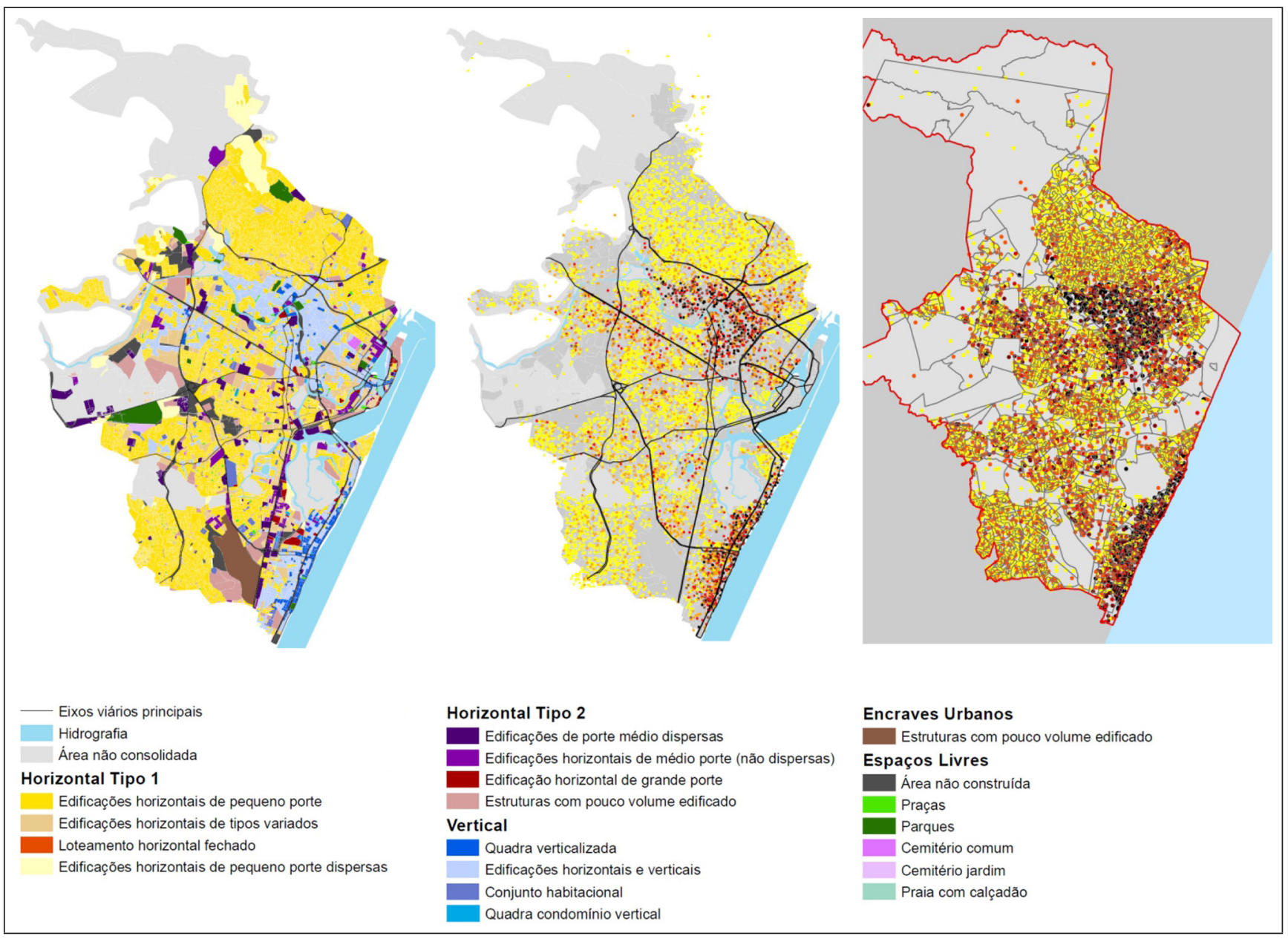




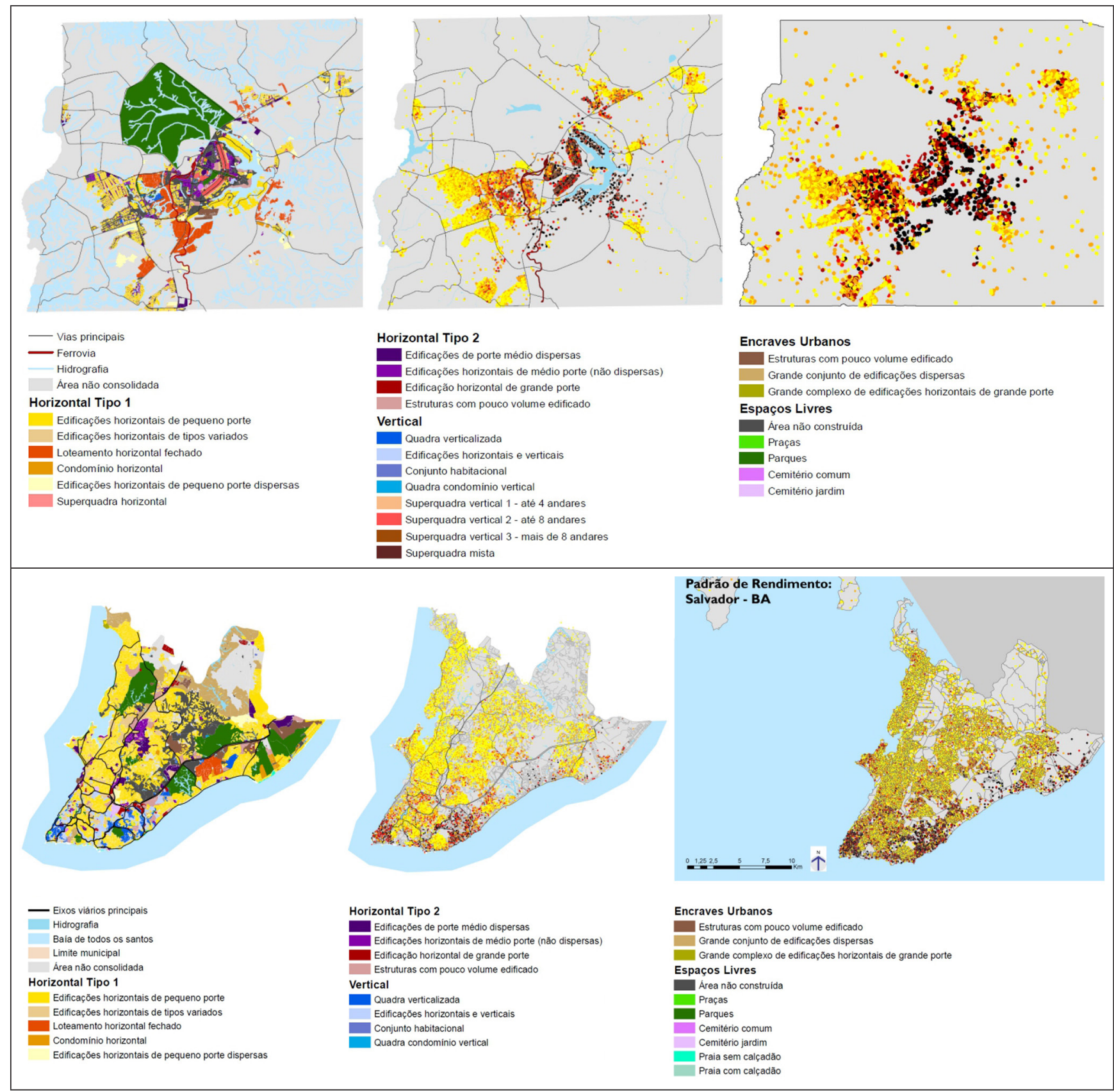

Figura 14 (topo): Aspecto Morfológico (esquerda); Aspectos demográficos (Centro); Mapa de Renda por responsável de domicílio (direita); Legenda do mapa de aspectos morfológicos de Brasília.

Figura 15: Aspecto Morfológico (esquerda); Aspectos demográficos (Centro); Mapa de Renda por responsáveis por domicílio (direita); Legenda do mapa de aspectos morfológicos de Salvador.

Fontes: Jonathas Magalhães Pereira da Silva e acervo do grupo de pesquisa, 2016.
Já no caso de Brasília as maiores rendas têm localização coincidente com os loteamentos horizontais fechados, superquadras na área do plano piloto e de quadras verticalizadas no caso do bairro de Águas Claras. As baixas rendas têm localização coincidente com edificações horizontais de pequeno porte e médio porte.

No município de Salvador as maiores rendas têm localização coincidente com as quadras de condomínio vertical e quadras verticalizadas nas localidades da Barra e Pituba. Nas localidades do Jaguaribe e Praia Stella Maris, a noroeste, existe uma concentração de responsáveis por domicílios com média e alta renda que coincide com edificações horizontais de pequeno porte. As baixas rendas têm localização coincidente com edificações horizontais de pequeno porte e médio porte. 


\section{Questões a serem consideradas}

Como urbanista nos interessa discutir os processos sociais que impactam na maneira do sujeito viver nas cidades e por consequência na forma urbana. Temos por meio desta formação domínio em analisar os suportes físicos, palcos das disputas sociais, e de identificar como o suporte irá interagir com os pactos sociais que constroem as legislações urbanas e que caracterizam as gestões e políticas públicas que incidem sobre a cidade. Entretanto devemos ainda alertar que imaginamos que algumas das questões aqui colocadas devem encontrar suas respostas em outras áreas das ciências como a Demografia ou a Economia, das quais não temos domínio. Desta forma os esforços por lançar estas questões, por meio do presente texto, têm como objetivo a documentação de forma a facilitar o intercambio dos saberes.

O presente trabalho lança uma serie de questões:

Existe relação entre a localização das rendas e a forma urbana?

Será esta relação tão obvia ou varia conforme a cultura e suporte físico local?

Os padrões identificados de renda, que indicam diferentes contextos de distribuição de renda, interferem na forma urbana? É possível estabelecer uma relação?

O padrão que indica uma boa distribuição das pessoas responsáveis dos domicílios de média e alta renda sobre o território municipal tem influência na forma urbana e sua estrutura de mobilidade?

As oportunidades de emprego e padrões de distribuição de renda podem de forma combinada interferir na forma urbana?

Para que avancemos nos estudos das cidades brasileiras que têm diferentes contextos de renda e aspectos morfológicos não será interessante identificarmos os padrões existentes?

Não seria pertinente incentivar pesquisas comparativas que não estabeleçam os padrões antes da realização das analises?

Estas questões são possíveis de responder se caminharmos para uma maior interdisciplinaridade assim como reforçarmos os esforços de analise do material que o grupo de pesqisa vem produzindo.

\section{Referências bibliográficas}

BENFATTI, Denio M.; QUEIROGA, Eugenio F.; SILVA, Jonathas M. Transformações da metrópole contemporânea: novas dinâmicas espaciais, esfera da vida pública e sistemas de espaços livres. Revista Brasileira de Estudos Urbanos e Regionais, v.12. n.1. p. 29-43, maio 2010.

CARVAlhaES, F. A. O.; BARBOSA, R. J.; SOUZA, P. H. G. F.; RIBEIRO, C. A. C. Os impactos da geração de empregos sobre as desigualdades de renda - Uma análise da década de 2000, Revista Brasileira de Ciências Sociais, Vol. 29 n 85, junho 2014.

CARVALHO, A. S. Vivendo às margens: Habitação de Interesse Social e o processo da segregação socioespacial em Curitiba. Florianópolis: PGAU-UFSC. (Dissertação(Mestrado PGAU), 2014. 
GUIMARÃES, N. A., Por uma sociologia do desemprego: contextos sociais, construções normativas e experiências subjetivas. Revista Brasileira de Ciências Sociais, 17 (50): 103-122, 2002.

LEMIEUX, T. (2006), "Increasing residual wage inequality: composition effects, noisy data, or rising demand for skill?". American Economic Review, 96 (3): 461-498.

LAMAS, José M. Ressano Garcia. Morfologia urbana e desenho da cidade. Fundação Calouste Gulbenkian \& Junta Nacional de Investigação Científica e Tecnológica. Lisboa. P. 592. 1992

MACEDO, S. S.; CUSTÓdIO, V ; GALENDER, Fany C ; QUEIROGA, e ; ROBBA, F. Os Sistemas de Espaços Livres e a Construção da Esfera Pública Contemporânea no Brasil. Uma Rede de Pesquisa em Âmbito Nacional. Paisagem e Ambiente, v. 23, p. 286-297, 2008.

MALDONADO COPELLO, María Mercedes. ¿Es posible anticiparse a la urbanización informal?: Reflexiones a partir de la Operación Urbanística Nuevo Usme, Bogotá, y del Macroproyecto Ciudadela Gonzalo Vallejo Restrepo, Pereira (Colombia) IN: LARANGEIRA, Adriana. Regularización de Asentamiento Informales en América Latina. Cambridge, EUA. CD Lincoln Institute of Land Policy, 2007. p. 324-343.

OLIVEIRA, D. Curitiba e o mito da cidade modelo. Curitiba: Ed. da UFPR, 2000.

SANCHEZ, F. E. G. Cidade espetáculo: política, planejamento e city marketing, Curitiba: Palavra, 1997

SANTOS, José Alcides Figueiredo. Estrutura de posições de classe no Brasil: mapeamento, mudanças e efeitos na renda. Belo Horizonte, Editora UFMG. 2002.

SINGER, Paul. O uso do solo urbano na economia capitalista, IN: MARICATO, Ermínia (Org.) A produção capitalista da casa (e da cidade) no Brasil industrial. São Paulo: Editora. Alfa-Omega Ltda, 1979. p.21-36.

SOUZA, N. R. Planejamento urbano, saber e poder. O governo do espaço e a população de Curitiba. São Paulo: Tese de doutorado - USP - FFLCH, 1999.

VILLAÇA, F. Espaço intra-urbano no Brasil. São Paulo: Fapesp, 2001. 